\title{
Under niche construction: an operational bridge between ecology, evolution, and ecosystem science
}

\author{
Blake Matthews, ${ }^{1,8}$ Luc De Meester, ${ }^{2}$ Clive G. Jones, ${ }^{3}$ Bas W. Ibelings, ${ }^{4}$ Tueerd J. Bouma,,${ }^{5}$ Visa Nuutinen, ${ }^{6}$ \\ Johan van de Koppel, ${ }^{5}$ and John OdLIng-SmeE ${ }^{7}$ \\ ${ }^{1}$ EAWAG, Aquatic Ecology Department, Center for Ecology, Evolution and Biogeochemistry, Kastanienbaum 6047 Switzerland \\ ${ }^{2}$ Laboratory of Ecology, Evolution and Conservation, University of Leuven, 3000 Leuven, Belgium \\ ${ }^{3}$ Cary Institute of Ecosystem Studies, P.O. Box AB, Millbrook, New York 12545 USA \\ ${ }^{4}$ University of Geneva, Institut FA Forel, 10 Route de Suisse, Versoix \\ ${ }^{5}$ Royal Netherlands Institute for Sea Research (NIOZ), Post Box 140, 4400 AC Yerseke, The Netherlands \\ ${ }^{6}$ MTT Agrifood Research Finland, FIN-31600 Jokioinen, Finland \\ ${ }^{7}$ Mansfield College, University of Oxford, Oxford OX13TF United Kingdom
}

\begin{abstract}
All living organisms modify their biotic and abiotic environment. Niche construction theory posits that organism-mediated modifications to the environment can change selection pressures and influence the evolutionary trajectories of natural populations. While there is broad support for this proposition in general, there is considerable uncertainty about how niche construction is related to other similar concepts in ecology and evolution. Comparative studies dealing with certain aspects of niche construction are increasingly common, but there is a troubling lack of experimental tests of the core concepts of niche construction theory. Here, we propose an operational framework to evaluate comparative and experimental evidence of the evolutionary consequences of niche construction, and suggest how such research can improve our understanding of ecological and evolutionary dynamics in ecosystems. We advocate for a shift toward explicit experimental tests of how organismmediated environmental change can influence the selection pressures underlying evolutionary responses, as well as targeted field-based comparative research to identify the mode of evolution by niche construction and assess its importance in natural populations.
\end{abstract}

Key words: alternative stable states; coevolution; diffuse coevolution; eco-evolutionary dynamics; ecoevolutionary feedbacks; ecosystem engineering; niche construction; trophic interactions.

\section{INTRODUCTION}

The basic premise of niche construction theory is that organisms can act as potent agents of natural selection by modifying biotic and abiotic environmental conditions (Lewontin 1983, Odling-Smee et al. 2003, 2013). Previous research on niche construction has extensively documented how living organisms, through their metabolism, activities, and choices, can alter their surrounding environment and by doing so influence prevailing selection pressures (Odling-Smee et al. 1996, 2003). Animals, for example, dig burrows, build nests, aerate soils, construct webs, and forage for prey, while plants photosynthesize, weather rocks, produce soil, and

Manuscript received 21 May 2013; revised 9 October 2013; accepted 22 October 2013. Corresponding Editor: N. J. B. Kraft.

${ }^{8}$ E-mail: blake.matthews@eawag.ch create shade (Odling-Smee et al. 2003). Such activities can modify the selective environment of the organism doing the environmental modification (Odling-Smee et al. 1996) or of an unrelated population (Odling-Smee et al. 2003, 2013). Organism-mediated environmental modifications can also persist through time and affect selection pressures experienced by future generations, a process referred to as ecological inheritance (OdlingSmee et al. 2003). Ecological inheritance is a key element of niche construction theory that is increasingly being integrated into evolutionary theory (Bonduriansky and Day 2009, Danchin et al. 2011, Bonduriansky 2012)

When using the term niche construction (Odling-Smee et al. 2003, 2013), niche refers to the sum of all natural selection pressures experienced by a population and construction refers to the modification of selection pressures, either through physical modification of the environment or through habitat choice (Odling-Smee et 
al. 2003). At the outset, niche construction theory focused on how organisms can modify their own selective environments (Odling-Smee et al. 1996), and so many classic examples of niche construction highlight the importance of reciprocal interactions between organisms and their own selective environment (Odling-Smee et al. 2003). Leaf cutter ants, for example, cultivate gardens of fungus upon which they are obligately dependent (Mueller and Gerardo 2002), and, in some cases, this has culminated in a loss of genes associated with the acquisition of specific nutrients (Ellers et al. 2012). Earthworms modify the structure of their soil environment in a way that facilitates water uptake into their bodies, thereby partially solving a critical physiological problem associated with living in terrestrial environments (Turner 2002). However, it is increasingly evident that organism-mediated environmental modifications can have a wide range of direct and indirect evolutionary effects on multiple species in natural communities (Odling-Smee et al. 2013, Walsh 2013). Odling-Smee et al. (2003) describe one type of indirect evolutionary effect as an environmentally mediated genotypic association (EMGA), which is an association that develops between distinct genotypes in the environment mediated by the effect of organisms on biotic or abiotic conditions. For example, earthworms might influence the selective environment experienced by plants growing in the same soils, potentially leading to covariance between the plant's fitness and the worm's genes that underlie modifications to the soil environment (Odling-Smee et al. 2003).

Clarifying the relationship between environmentmodifying activities of organisms and fitness variation has been controversial throughout the development of niche construction theory (Dawkins 2004, Laland and Sterelny 2006). Dawkins (2004) argues that the buildup of covariance between fitness and phenotype is much more likely to occur within a gene pool, consistent with the idea of an extended phenotype (Dawkins 1982), rather than across gene pools (Dawkins 2004). In the case of an extended phenotype, the phenotypic trait that underlies the organism-mediated modifications of the environment must vary within a population, have a genetic basis, and be the target of the altered selection regime caused by the environmental modifications (Dawkins 2004, Brodie 2005). For example, genetically based variation among gall wasps in their ability to construct oak galls can affect rates of parasitoid infection in the next generation of gall wasps, leading to a covariance between gall forming traits and offspring fitness (Bailey et al. 2009). While not disputing the importance of extended phenotypes, niche construction theory (Odling-Smee et al. 2003) argues that the traits underlying specific environmental modifications neither need to have a strong genetic basis (for example, they can be acquired characters) nor need to be the same traits that develop strong associations with fitness. Hence, compared to Dawkins (2004), Odling-Smee et al. $(2003,2013)$ consider a broader range of selective agents that can potentially drive evolution, and suggest that covariance between fitness and phenotype can frequently build up across species, resulting from organism-mediated modifications to both biotic and abiotic environmental conditions. While empirical data and theoretical work are increasingly supporting this view (Kerr et al. 1999, Odling-Smee et al. 2003, Krakauer et al. 2009, Laland and Boogert 2010, Kylafis and Loreau 2011), the ongoing challenge is to determine how much of the variance in fitness of one organism can be explained by organism-mediated environmental modifications compared to other agents of selection.

Since its inception, niche construction theory has captured the attention of a wide range of evolutionary biologists, ecologists, and philosophers (Erwin 2008, Lehmann 2008, Krakauer et al. 2009, Post and Palkovacs 2009, Loreau 2010, Kylafis and Loreau 2011, Van Dyken and Wade 2012), but has also provoked considerable debate as to its novelty (Brodie 2005), scope (Okasha 2005, Kylafis and Loreau 2008), and usefulness (Dawkins 2004). Niche construction has been defined with a deliberately broad scope (Laland and Sterelny 2006), and this has offered ecologists new insights about how modifications to the environment by organisms might persist over time (e.g., ecological inheritance), result from byproducts and acquired characters (Odling-Smee et al. 2003), and interact with other environmental sources of selection so as to influence evolutionary change in natural populations (Odling-Smee et al. 2013).

While generally received sympathetically, the broad scope of niche construction theory has nonetheless led to some confusion and conflicts about how aspects of the theory are positioned in relation to other closely related ideas in both ecology and evolution. For example, the concept of reciprocal interactions between organisms and their selective environments is both fundamental to niche construction theory and long-established in some areas of standard evolutionary theory (Fisher 1930, Roughgarden 1976, Crespi 2004, Frank 2009), particularly in classic work on coevolution and diffuse coevolution (Thompson 2005, Haloin and Strauss 2008). In ecology, there is also some uncertainty about precisely what new insights niche construction theory can offer. On the one hand, niche construction theory has already made important contributions to emerging syntheses between ecological and evolutionary dynamics (Fussmann et al. 2007, Kokko and López-Sepulcre 2007, Post and Palkovacs 2009, Kylafis and Loreau 2011, Matthews et al. 2011b, Schoener 2011). In particular, niche construction research has documented a broad range of organism-mediated environmental modifications that can influence selection pressures (Odling-Smee et al. 2003). With the growing realization that ecological and evolutionary timescales can be congruent (Hairston et al. 2005, Ellner et al. 2011), such environmental modifications might turn out to be more important 
agents of selection and drivers of evolutionary change than previously thought (Odling-Smee et al. 2013). On the other hand, the precise relationship between niche construction theory and eco-evolutionary dynamics is unclear, and there is confusion about how niche construction is related to other ecological concepts in general, and to ecosystem engineering in particular (Odling-Smee et al. 2003, Boogert et al. 2006, Pearce 2011). Even though ecosystem engineering theory clearly recognizes that the engineering effects of organisms can have important evolutionary consequences (Jones et al. 1994), the strict definitions of ecosystem engineering (Jones et al. 1994, 1997) and niche construction (OdlingSmee et al. 1996, 2003) refer to distinct concepts.

In our view, niche construction theory has the potential to bridge many related concepts in ecology, evolution, and ecosystem science. With the goal of integration in mind, Odling-Smee et al. (2013) recently distinguished between two important "aspects" of the process of niche construction. The first aspect is the environment-altering activities of organisms, and the second is the subsequent modification of the selective environment (Odling-Smee et al. 1996, 2003, 2013). Niche construction is only present if both aspects occur, as not all environmental modifications will alter selection pressures. Similarly, not all changes to selection pressures will cause an evolutionary response, meaning that niche construction can occur without influencing evolution. In order to evaluate the importance of evolution by organism-mediated environmental modification in natural populations, we need to translate niche construction theory into empirical practice (Odling-Smee et al. 2013). To do this, we propose the following criteria to test for the presence of niche construction (Criteria 1 and 2) and determine when niche construction affects evolution (Criterion 3).

1) An organism (i.e., a candidate niche constructor) must significantly modify environmental conditions.

2) The organism-mediated environmental modifications must influence selection pressures on a recipient of niche construction.

3) There must be a detectable evolutionary response in a recipient of niche construction that is caused by the environmental modification of the niche constructor.

Here, we refer to the environment in relation to both biotic and abiotic characteristics, and the selective environment as the environmental context in which natural selection occurs. The first two criteria define the term niche construction (Odling-Smee et al. 2013). The organism changing the environmental conditions is only classified as a niche constructor if Criterion 2 is satisfied. The third criterion is a test of evolution by niche construction, or in other words, evolution via selection that is mediated by organismal modification of the environment. We consider an evolutionary response as a genetic change in a population that alters the relationship between the phenotype distribution (including mean, variance, and other moments of the distribution) and fitness variation. We distinguish between a niche constructor and a recipient of niche construction, but explicitly recognize that both can refer to the same organism. For example, in the case of an extended phenotype, the niche constructor and recipient of niche construction would be organisms within the same gene pool, whereas in the case of an environmentally mediated genotypic association, the niche constructor and recipient could be different species.

Using these three criteria we can evaluate which sets of ecological and evolutionary interactions describe evolution by niche construction, and which do not. We summarize this approach graphically in Fig. 1 where we consider a wide range of scenarios in which organisms are connected with their biotic and abiotic environment via pathways of evolutionary (dashed arrows) and nonevolutionary (solid arrows) effects. Evolutionary effects are those cases where organisms cause an evolutionary response (e.g., Criterion 3), while non-evolutionary effects include the effects organisms have on the abundance, distribution, and behavior of interacting biota (e.g., collectively referred to as ecological effects), as well as effects on the physical (e.g., engineering effects) and chemical state of their environment (Criterion 1; Fig. 2A). For a particular scenario in Fig. 1 to satisfy evolution by niche construction (i.e., the minimum condition for satisfying Criterion 3), the pathway of effects must start (from the left) with a niche constructor, it must include at least two sequential effects (i.e., connections in sequence along the pathway of effects), and there must be an evolutionary effect beyond the first effect. This last condition follows from our second criterion, which requires selection pressures to be mediated through some form of environmental modification by an organism, including changes to either abiotic or biotic conditions (Fig. 2). Evolution by niche construction does not occur for scenarios where the evolutionary response of an organism is caused solely by the direct selection effects of another organism or by an environmental condition that is unmodified by another organism. Such scenarios are examples of evolution, but not of evolution by niche construction (Fig. 1). Following our scheme, there are many simple modules of ecological interactions that do not meet all three criteria (Fig. 1, modules within the ecology box but outside the evolution box). This highlights that there is considerable scope for ecologists to use niche construction theory to help integrate evolution and ecosystem ecology. To facilitate this, we clarify how niche construction (Criteria 1 and 2) and evolution by niche construction (Criterion 3) are related to several key concepts, such as: ecosystem engineering, (diffuse) coevolution, and eco-evolutionary dynamics and feedbacks.

Ecosystem engineering.-The distinction between ecosystem engineering and niche construction is currently unclear in the literature (Boogert et al. 2006, Post and 


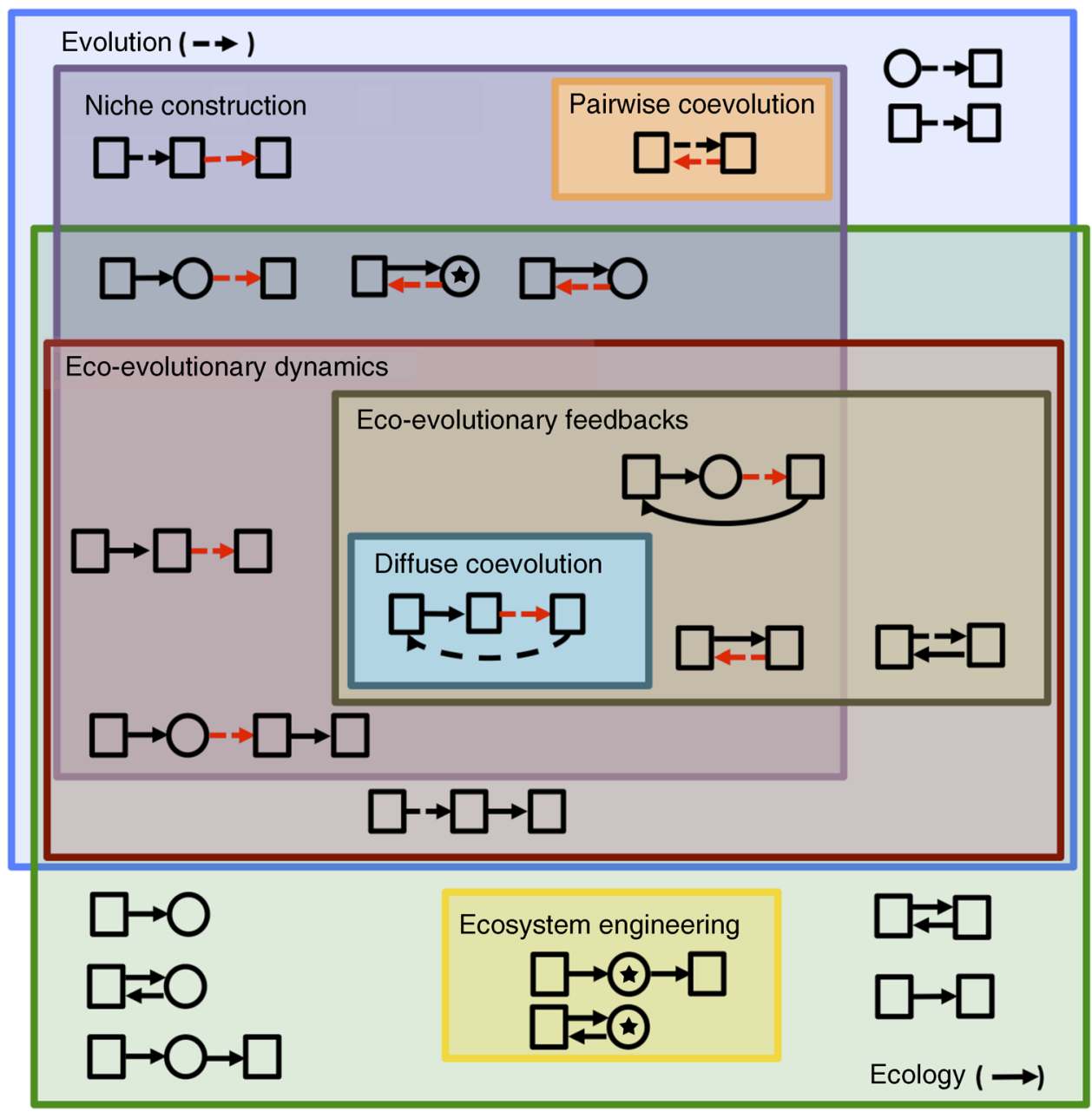

FIG. 1. A Venn diagram showing which modules of biotic (square) and abiotic (circles) entities, which are connected by evolutionary (dashed lines) and non-evolutionary effects (solid lines), are associated with different major concepts in ecology and evolution (bounded by labeled shaded boxes). Non-evolutionary effects include organism-mediated effects on both biotic and abiotic conditions (e.g., ecological effects shown in Fig. 2A), and evolutionary effects include evolutionary responses to selection. The stars denote effects on the physical state of the abiotic environment, to distinguish ecosystem engineering (yellow box) from effects on other abiotic conditions (e.g., the chemical environment). The minimum condition for evolution by niche construction to occur is to have a pathway that starts and ends with an organism (i.e., a niche constructor and a recipient of niche construction), and has at least two connections with an evolutionary effect beyond the first connection. Starting from the left of each pathway the red dashed arrow defines where evolution by niche construction has occurred.

Palkovacs 2009, Pearce 2011, Odling-Smee et al. 2013). Ecosystem engineers are organisms that modify their physical surroundings (e.g., light environment, physical habitat structure) so as to modulate the availability of resources or energy fluxes in an ecosystem (Jones et al. 1994, 1997). By comparison, niche constructors are organisms that alter selection pressures of a recipient organism by modifying any aspect of the abiotic and biotic environment (Fig. 2). Evidence of ecosystem engineering would only satisfy our first criterion, and would not provide evidence of niche construction. Nevertheless, ecosystem engineers are excellent candidates for being niche constructors because their effects on the physical environment can propagate to influence chemical fluxes and species interactions, and cause ecosystem effects that are large, multidimensional, and persistent (Wright and Jones 2006, Hastings et al. 2007, Jones 2012). Ecosystem engineering is hence a putative mechanism of niche construction, and further work should focus on the how engineers might alter selection pressures on themselves or on other species (Criterion 2).

Coevolution and diffuse coevolution.-Based on our criteria and schematic (Fig. 1), all examples of pairwise coevolution and diffuse coevolution are examples of evolution by niche construction. Pairwise coevolution is the situation where two interacting organisms are both niche constructors and recipients of niche construction (Fig. 2B) and they both drive reciprocal evolutionary 
responses on one another. Diffuse coevolution is the case where a niche constructor drives an evolutionary response of a recipient that is a different species, and where this response is mediated through the niche constructors's ecological or evolutionary effect on another species that interacts with the recipient (Haloin and Strauss 2008). Hence, diffuse co-evolution is equivalent to evolution by niche construction where the selective environment is modified by species interactions in the community. In sum, compared to all forms of coevolution, evolution by niche construction considers a broader range of potential agents of selection and effect pathways that underlie evolutionary responses (Fig. 1).

Eco-evolutionary dynamics.-The emerging field of eco-evolutionary dynamics has a very broad focus that includes both the ecological and evolutionary responses of populations to interactions between organisms and their environment (Fussmann et al. 2007, Urban et al. 2008, Post and Palkovacs 2009, Matthews et al. 2011b, Schoener 2011). Eco-evolutionary dynamics grew out the recognition that population dynamics and phenotypic evolution can occur on similar timescales, leading to an important contemporary interplay between evolutionary and ecological dynamics in natural populations (Thompson 1998, Hairston et al. 2005, Schoener 2011). Evolution by niche construction is closely related to eco-evolutionary dynamics but the two concepts have slightly different emphases and are distinguishable in our schematic (Fig. 1). Although the distinction is often likely to be subtle, it is useful to identify the minimum conditions that constitute each process in order to perform more targeted experimental tests of the specific mechanisms. Eco-evolutionary dynamic scenarios must include at least two organisms and at least one evolutionary and one ecological effect (i.e., a nonevolutionary effect terminating with a biotic recipient). Neither of these two conditions is necessary for evolution by niche construction.

Following our scheme, there are simple cases of evolution by niche construction that do not constitute eco-evolutionary dynamics, and vice versa (Fig. 1). Unlike eco-evolutionary dynamics, evolution by niche construction includes scenarios made up of entirely evolutionary effects (Fig. 1), including linked chains of evolutionary effects (e.g., evolutionary cascades) and reciprocal evolutionary effects (e.g., coevolution). In addition, evolution by niche construction includes simple scenarios where an evolutionary effect follows from an organism's effect on abiotic environmental conditions. In relation to Fig. 1, for example, worms (square) can modify (solid arrow) the soil environment (circle) and affect the evolution (dashed arrow) of plants (square). Such chains of interactions where abiotic modifications influence selection pressures are an important emphasis of niche construction theory (Odling-Smee et al. 2013) but in their simplest form can fall

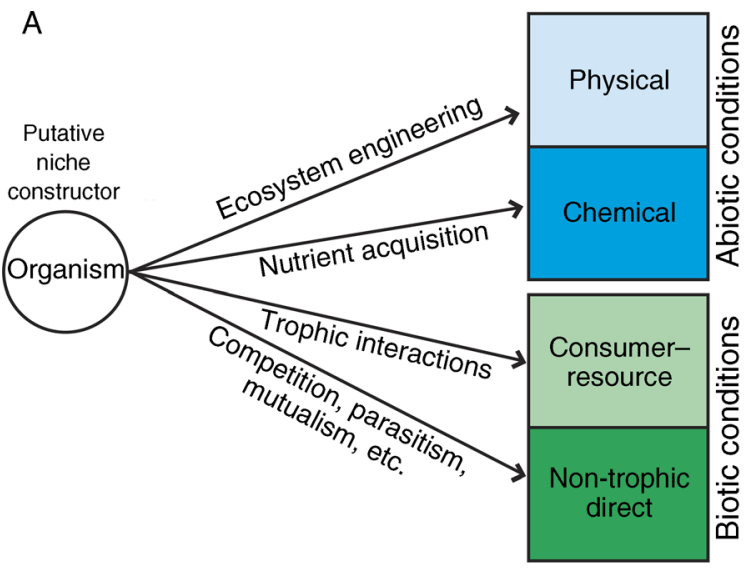

B

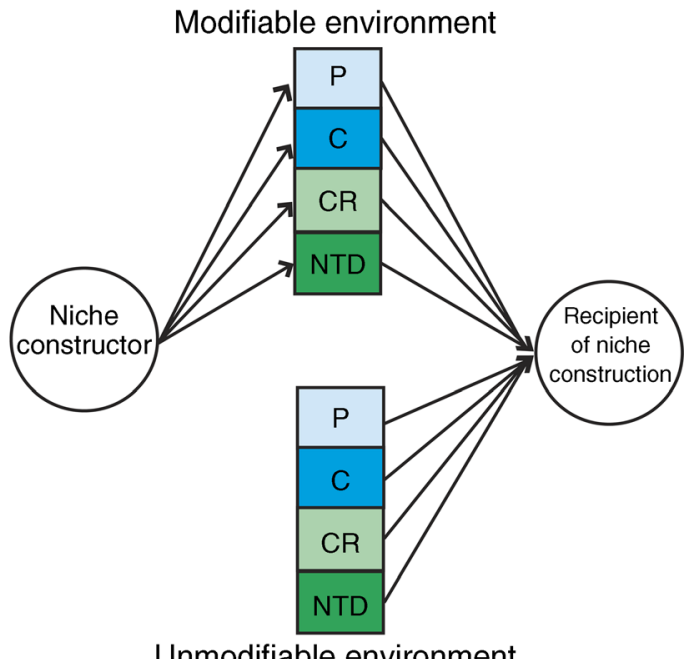

Unmodifiable environment

FIG. 2. (A) A partitioning of how organisms can modify their biotic and abiotic environments. (B) An elaboration of how organism mediated environmental modifications can affect the fitness of another organism (e.g., potentially a recipient of niche construction), through a variety of pathways (abbreviated following Fig. 2A: P, physical; C, chemical; CR, consumerresource; NTD, non-trophic direct). Niche construction can occur when organism-mediated environmental modifications alter the evolutionary response of organisms relative to other environmental drivers of selection (e.g., unmodifiable environment).

outside the domain of eco-evolutionary dynamics (Fig. 1).

Eco-evolutionary dynamics scenarios can also occur without evolution by niche construction. In relation to Fig. 1, for example, a predator (square) may cause an evolutionary response (dashed arrow) in the life history of a prey population (circle) that subsequently changes prey consumption rates (solid arrow) on a resource (circle). This is illustrated by recent work showing that alewives, a common planktivorous fish in freshwater lakes of eastern North America, drive evolution in Daphnia in a way that alters their grazing rates on 
phytoplankton (Walsh et al. 2012). This particular example does not meet our second criterion for niche construction, because the selection pressure of alewives on Daphnia is not mediated by an environmental modification caused by alewives. In more complicated scenarios, evolution by niche construction and ecoevolutionary dynamics will likely overlap, particularly when there are multiple interacting species and complex networks of ecological and evolutionary effects. This may also be true for the alewife system, where there is additional evidence for eco-evolutionary feedbacks and niche construction (Palkovacs and Post 2008, Post and Palkovacs 2009).

Eco-evolutionary feedbacks. - Eco-evolutionary feedbacks are a specific type of eco-evolutionary dynamics that describe a reciprocal interaction between an ecological and evolutionary process (Post and Palkovacs 2009). To provide evidence of evolution by niche construction an eco-evolutionary feedback must include an evolutionary response to organism-mediated changes in the environment (Fig. 1). Eco-evolutionary feedbacks do not always satisfy the criteria for niche construction (Criterion 2) or for evolution by niche construction (Criterion 3). In some situations, the sequence of the linked effects can be important for identifying evolution by niche construction.

Eco-evolutionary feedbacks that begin with an ecological effect and subsequently cause an evolutionary effect are clearly classified as evolution by niche construction. For example, migratory and landlocked populations of the alewives can have contrasting effects on the composition and size structure of their prey communities (Palkovacs and Post 2008), and this is thought to generate divergent selection and contribute to the phenotypic divergence among allopatric populations of alewives (Post and Palkovacs 2009). In this case, evolution by niche construction has occurred if the ecological effects of alewives (i.e., changes in prey species composition, or life history of a specific prey) drive phenotypic evolution of the alewives themselves, or indirectly cause an evolutionary response of some other organism in the system. Recently, Walsh et al. (2012) reviewed several studies that piece together the network of ecological and evolutionary interactions between alewives, zooplankton, and phytoplankton. Together these studies provide growing evidence for eco-evolutionary feedbacks and niche construction in natural populations.

Eco-evolutionary feedbacks that begin with an evolutionary effect may or may not be classified as evolution by niche construction. Consider an ecoevolutionary feedback in which a predator is both causing the evolutionary effect on a prey species and is the recipient of the ecological effect from the altered evolution of the prey. If the ecological effect that feeds back on the predator subsequently modifies the predator's evolutionary effect on the prey, then this would constitute evolution by niche construction (Criterion 3).
For example, in relation to Fig. 1, evolution by niche construction would occur if the predator (circle) directly alters the genotype distribution (dashed arrow) of prey (circle), this has a feedback on the population dynamics of the predator (solid arrow), and this subsequently changes the predator's effect on the genotype distribution (dashed arrow) of prey. This is analogous to situations where predator-mediated selection pressures are dependent on densities of predators and prey (i.e., density- and frequency-dependent selection). Evolution by niche construction would not occur if the evolutionary responses of the prey were independent of (or insensitive to) variation in predator density, because the ecological effects of prey evolution on predator population dynamics would have no further influence on prey evolution. In such a scenario, an eco-evolutionary feedback could occur in the absence of evolution by niche construction. Again, we acknowledge this is subtle distinction between eco-evolutionary feedbacks and evolution by niche construction, but such considerations might help to decipher the mechanisms underlying coupled ecological and evolutionary dynamics.

So far, we have used our criteria to clarify how key elements of niche construction theory are positioned relative to other closely related concepts in ecology and evolution. In the following sections, we (1) use our criteria to evaluate evidence of niche construction from a wide range of studies and to identify new research directions, (2) present new comparative and experimental approaches for testing several elements of niche construction theory, and (3) describe a well-established model system in ecology that is useful for studying evolution by niche construction in natural ecosystems.

\section{Bridging Disciplinary Gaps with Niche Construction RESEARCH}

We surveyed a wide selection of literature that was relevant to understanding the multiple facets of niche construction theory and used our criteria to identify potential future avenues of research (Table 1). Although our review is not exhaustive, it illustrates the following three issues: (1) some of the potential mechanisms of niche construction (Fig. 2) are well studied while others are not (Table 1; Gap I), (2) several research areas in ecology and evolution could be expanded to test for new examples of evolution by niche construction by measuring evolutionary responses of organism-mediated environmental modifications (Table 1; Gap II), (3) many studies that explicitly discuss niche construction are based on comparative evidence and would benefit from additional experimental support (Table 1, see Criteria column).

\section{Broaden the study of potential niche construction mechanisms: Table 1, Gap I}

There are numerous mechanisms by which organisms can modify their environment, and parsing these out (Fig. 2A) can provide clues about the potential fitness 
TABLE 1. A summary of studies illustrating multiple facets of niche construction theory.

\begin{tabular}{|c|c|c|c|c|c|c|c|c|}
\hline Niche constructor and recipient & Criteria & $\mathrm{C}_{\mathrm{M}}$ & $P_{\mathrm{M}}$ & $\mathrm{CR}_{\mathrm{M}}$ & $\mathrm{NTD}_{\mathrm{M}}$ & $\mathrm{NC}$ & cipient & Citation \\
\hline \multicolumn{9}{|l|}{ Niche construction theory } \\
\hline $\begin{array}{l}\text { Vascular plants decreased } \mathrm{CO}_{2} \text { by accelerating } \\
\text { weathering and carbon burial }\end{array}$ & $1,(2,3)$ & $\mathrm{x}$ & $\mathrm{x}$ & & & $\mathrm{x}$ & $\mathrm{x}$ & Beerling (2005) \\
\hline $\begin{array}{l}\text { Cowbirds socially manufacture compliant } \\
\text { hosts to increases parasitic egg survival }\end{array}$ & $1,2,(3)$ & & & & $\mathrm{x}$ & $\mathrm{x}$ & & Hoover and Robinson (2007) \\
\hline $\begin{array}{l}\text { Earthworms modify soil structure and water } \\
\text { holding capacity to maintain osmotic } \\
\text { balance }\end{array}$ & $1,(2,3)$ & $\mathrm{x}$ & $\mathrm{x}$ & & & $\mathrm{x}$ & & Turner (2002) \\
\hline $\begin{array}{l}\text { Ants culture fungi to avoid cellulose } \\
\text { metabolism }\end{array}$ & $1,(2,3)$ & & & $\mathrm{x}$ & $\mathrm{x}$ & $\mathrm{x}$ & & Mueller and Gerardo (2002) \\
\hline $\begin{array}{l}\text { Bioturbators of sediments promote radiations } \\
\text { of Cambrian species }\end{array}$ & $1,(2,3)$ & $\mathrm{x}$ & $\mathrm{x}$ & & & $\mathrm{x}$ & $\mathrm{x}$ & Erwin and Tweedt (2011) \\
\hline $\begin{array}{l}\text { Sequential speciation whereby host diversity } \\
\text { promotes diversity of parasites }\end{array}$ & $1,(2,3)$ & & & & $\mathrm{x}$ & $\mathrm{x}$ & $\mathrm{x}$ & Forbes et al. (2009) \\
\hline $\begin{array}{l}\text { Stabilization of social networks by policing } \\
\text { increases infant survival rates of mammals }\end{array}$ & $1,(2,3)$ & & & & $\mathrm{x}$ & $\mathrm{x}$ & & Flack et al. (2006) \\
\hline $\begin{array}{l}\text { Heat production during fermentation by } \\
\text { Saccharomyces cerevisiae increases fitness } \\
\text { relative to other yeasts }\end{array}$ & $1,2,3$ & $\mathrm{x}$ & $\mathrm{x}$ & & & $\mathrm{x}$ & & Goddard (2008) \\
\hline $\begin{array}{l}\text { Evolution of seed dispersal in Arabidopsis } \\
\text { modifies environmental conditions and } \\
\text { relative fitness of seed genotypes }\end{array}$ & 1,2 & & & & $\mathrm{x}$ & $\mathrm{x}$ & & Donohue et al. (2005) \\
\hline $\begin{array}{l}\text { Caullerpa taxifolia alters selection gradients } \\
\text { of the co-occurring bivalve }\end{array}$ & 1,2 & & & & $\mathrm{x}$ & & $\mathrm{x}$ & Wright et al. (2012) \\
\hline \multicolumn{9}{|l|}{ Extended phenotype } \\
\hline $\begin{array}{l}\text { Gallwasps create oak galls to avoid } \\
\text { parasitoids }\end{array}$ & $1,(2,3)$ & & $\mathrm{x}$ & & & $\mathrm{x}$ & & Bailey et al. (2009) \\
\hline $\begin{array}{l}\text { Trematodes cause limb malformation that } \\
\text { increase amphibian susceptibility to } \\
\text { predation }\end{array}$ & $1,2,(3)$ & & & $\mathrm{x}$ & $\mathrm{x}$ & $\mathrm{x}$ & & Goodman and Johnson (2011) \\
\hline $\begin{array}{l}\text { Baculovirus changes host behavior to increase } \\
\text { transmission }\end{array}$ & $1,(2,3)$ & & & & $\mathrm{x}$ & $\mathrm{x}$ & & Hoover et al. (2011) \\
\hline \multicolumn{9}{|l|}{ Evolutionarily focused studies } \\
\hline \multicolumn{9}{|l|}{ Coevolution } \\
\hline $\begin{array}{l}\text { Coevolving pathogens favor the evolution } \\
\text { of sex in nematodes }\end{array}$ & $1,2,3$ & & & & $\mathrm{x}$ & $\mathrm{x}$ & $\mathrm{x}$ & Morran et al. (2011) \\
\hline \multicolumn{9}{|l|}{ Diffuse co-evolution } \\
\hline $\begin{array}{l}\text { Pine cone consumers shape selection } \\
\text { pressures on crossbills }\end{array}$ & $1,2,3$ & & & $\mathrm{x}$ & & & $\mathrm{x}$ & Benkman et al. (2010) \\
\hline $\begin{array}{l}\text { Herbivore community affects evolution of } \\
\text { plant resistance to grazing }\end{array}$ & $1,2,(3)$ & & & & $\mathrm{x}$ & & $\mathrm{x}$ & Stinchcombe and Rausher (2002) \\
\hline \multicolumn{9}{|l|}{ Character displacement } \\
\hline $\begin{array}{l}\text { Competition for seeds drive divergence in } \\
\text { Finch beak shape }\end{array}$ & $1,(2,3)$ & & & $\mathrm{x}$ & & $\mathrm{x}$ & $\mathrm{x}$ & Grant and Grant (2006) \\
\hline \multicolumn{9}{|l|}{ Speciation } \\
\hline $\begin{array}{l}\text { Ecological speciation of stickleback via } \\
\text { divergent natural selection }\end{array}$ & $1,2,3$ & & & $\mathrm{x}$ & $\mathrm{x}$ & $\mathrm{x}$ & $\mathrm{x}$ & Schluter (2009) \\
\hline \multicolumn{9}{|l|}{ Ecologically focused studies } \\
\hline \multicolumn{9}{|l|}{ Ecosystem engineering } \\
\hline Riparian plants structure fluvial landscapes & 1 & & $\mathrm{x}$ & & & & & Corenblit et al. (2009) \\
\hline Beavers build dams and flood landscapes & 1 & & $\mathrm{x}$ & & & & & Jones et al. (1994) \\
\hline $\begin{array}{l}\text { Spartina modifies sediment accumulation } \\
\text { and size structure }\end{array}$ & 1 & & $\mathrm{x}$ & & & & & Bouma et al. (2010) \\
\hline $\begin{array}{l}\text { Sticklebacks modify light environments of } \\
\text { aquatic ecosystems }\end{array}$ & 1 & & $\mathrm{x}$ & & & & & Harmon et al. (2009) \\
\hline $\begin{array}{l}\text { Earthworm invasion changes ecosystem } \\
\text { properties }\end{array}$ & 1 & & $\mathrm{x}$ & & & & & Hendrix (2006) \\
\hline \multicolumn{9}{|l|}{ Ecological stoichiometry } \\
\hline $\begin{array}{l}\text { Variation in stoichiometry of predators } \\
\text { affects nutrient cycling }\end{array}$ & 1 & $\mathrm{x}$ & & & & & & McIntyre et al. (2008) \\
\hline $\begin{array}{l}\text { Selection on growth rate of consumers } \\
\text { increases their P-demand }\end{array}$ & 1 & & & & & & & Sterner and Elser (2002) \\
\hline $\begin{array}{l}\text { Selection on stoichiometry of primary } \\
\text { producers }\end{array}$ & 1 & & & & & & & Mizuno and Kawata (2009) \\
\hline
\end{tabular}


TABle 1. Continued.

\begin{tabular}{|c|c|c|c|c|c|c|}
\hline Niche constructor and recipient & Criteria & $\mathrm{C}_{\mathrm{M}}$ & $P_{\mathrm{M}}$ & $\mathrm{CR}_{\mathrm{M}}$ & $\mathrm{NTD}_{\mathrm{M}} \mathrm{NC}$ Recipient & Citation \\
\hline \multicolumn{7}{|l|}{ Ecosystem effects of organisms } \\
\hline $\begin{array}{l}\text { Phenotypic variation of consumers affect } \\
\text { ecosystem properties and functions }\end{array}$ & 1 & $\mathrm{x}$ & $\mathrm{x}$ & $\mathrm{x}$ & $\mathrm{x}$ & Schmitz (2010) \\
\hline $\begin{array}{l}\text { Variation in consumer biomass affects } \\
\text { ecosystem properties and functions }\end{array}$ & 1 & $\mathrm{x}$ & $\mathrm{x}$ & $\mathrm{x}$ & $\mathrm{x}$ & Dickman et al. (2008) \\
\hline Predators drive trophic cascades & 1 & & & $\mathrm{x}$ & $\mathrm{x}$ & Carpenter and Kitchell (1993) \\
\hline $\begin{array}{l}\text { Organism-mediated shifts between } \\
\text { alternative stable states }\end{array}$ & $1,(2,3)$ & $\mathrm{x}$ & $\mathrm{x}$ & $\mathrm{x}$ & $\mathrm{x}$ & Scheffer et al. (2001) \\
\hline \multicolumn{7}{|l|}{ Species turnover } \\
\hline $\begin{array}{l}\text { Predators affect community assembly of } \\
\text { prey }\end{array}$ & 1 & & & $\mathrm{x}$ & $\mathrm{x}$ & Chase et al. (2009) \\
\hline \multicolumn{7}{|c|}{$\begin{array}{l}\text { Notes: Section headings list the primary focus of each research field. For each study (row), the first column summarizes how the } \\
\text { putative niche constructor (organisms in italic type) affects selection pressures on a recipient of niche construction (organisms in } \\
\text { boldface type). The second column indicates whether there is support for each criterion, coming either from only comparative } \\
\text { (number in parentheses) or both comparative and experimental evidence (see Introduction for a description of each criterion). The } \\
\text { next four columns identify with an x the modifiable (M subscript) characteristics of the environment, as illustrated in Fig. } 2 \text { (i.e., C, } \\
\text { chemical; P, physical; CR, consumer-resource interactions; and NTD, non-trophic direct interactions). The columns NC (niche } \\
\text { constructor) and Recipient indicate with an x which organisms are subject to changes in the selection pressures caused by the } \\
\text { organisms identified as doing the environmental modification. We identify of two research gaps in Bridging disciplinary gaps with } \\
\text { niche construction research; Gap I emerges from the lack of focus on } \mathrm{C}_{\mathrm{M}} \text { and } P_{\mathrm{M}} \text { (few xs) in evolutionarily focused studies and Gap } \\
\text { II arises from the lower emphasis on evolutionary responses of NC and Recipient (few xs) in ecologically focused studies. }\end{array}$} \\
\hline
\end{tabular}

effects on recipient organisms (Fig. 2B). To begin, it is useful to partition the environment into components that are either modifiable or un-modifiable by a particular organism over a relevant timescale necessary to assess a change in selection pressures or to track an evolutionary response in a recipient organism. We then split each environmental partition into the four categories shown in Fig. 2A, which we discuss below, as a way to summarize the wide range of potential mechanisms of niche construction that we have identified from previous studies (Table 1).

Abiotic effects: physical.-The ubiquity of ecosystem engineers across a range of natural systems testifies to the capacity for organisms to strongly modify their physical environment (Fig. 2A). Interestingly, such effects can also have strong cascading effects on other biotic and abiotic factors (Jones et al. 1994, Hastings et al. 2007), but very little is known about how ecosystem engineers mediate selection pressures and drive evolutionary responses in natural populations.

Abiotic effects: chemical.-Organisms with strong nutrient homeostasis (Sterner and Elser 2002) can affect their chemical environment through the acquisition and regeneration of resources (Fig. 2A). The evolution of consumer elemental ratios (e.g., C:N:P) is often closely related to growth, such that variation in the growth rate among organisms can have major impacts on biologically mediated flows of chemicals in the environment (Sterner and Elser 2002). Feedbacks between consumer growth rate and modifications to the chemical environment have been addressed by theory (Mizuno and Kawata 2009), but little is known about how variation in organismal $\mathrm{C}: \mathrm{N}: \mathrm{P}$ ratios might affect selection pressures in nature.
Biotic effects: consumer resource interactions.- - Hostparasite and predator-prey interactions are both archetypal consumer-resource interactions (Fig. 2A) and provide some of the best empirical examples of how organisms can modify their biotic environment (Holt and Lawton 1994, Lafferty et al. 2008). Predators, for example, can have strong effects on community structure (Chase et al. 2009) and ecosystem functions (Schmitz 2010) and can drive eco-evolutionary feedbacks (Post and Palkovacs 2009, Becks et al. 2012). The prevalence of trait-mediated indirect effects (Werner and Peacor 2003, Walsh 2013) suggests a rich set of ways that consumers can alter selection pressures through modification of biotic interactions.

Biotic effects: non-trophic direct interactions.-Nontrophic direct interactions between species (Olff et al. 2009) can also drive changes to the biotic environment leading to altered selective environments (Fig. 2A). This category of potential mechanisms of niche construction reflects the non-consumptive activities of organisms that might lead to evolutionary changes, such as interference competition, cooperation, induced defense, and behavioral modification. As one example, the relationship between a plant's fitness and its tolerance to herbivory by deer (i.e., a selection gradient) is influenced by whether insect herbivores are active in the system (Stinchcombe and Rausher 2002).

Partitioning the mechanisms of organism-mediated environmental effects (e.g., Fig. 2) provides a structure for isolating the interactions underlying organismal effects on selective environments (Criterion 2) and for detecting subsequent evolutionary responses (Criterion 3 ). In general, very little is known about how organismmediated modifications to the chemical and physical 
state of the environment can affect selection pressures (Gap I in Table 1). Among the more evolutionarily oriented studies in our literature review, the greater focus on the biotic effects (MacColl 2011) over the abiotic effects (Jones et al. 1994) of organisms is symptomatic of the limited cross-fertilization of ideas between evolutionary biology and ecosystem ecology (Matthews et al. 2011b). For example, there is considerable experimental work aimed at deciphering which species interactions underlie the divergent selection regimes that drive ecological speciation (Schluter 2000, Nosil 2012), but there is much less research about how recent adaptive divergence between closely related species can affect abiotic environmental conditions (Harmon et al. 2009), and no experimental tests about whether such effects can influence selection pressures so as to either promote or constrain further evolutionary divergence (Losos 2010, Yoder et al. 2010)

It is important to identify the modifiable components of the environment that might underly selection pressures (Criterion 2) and drive evolutionary responses (Criterion 3), because multiple interacting agents of selection can lead to complex relationships between fitness and phenotype (Wade and Kalisz 1990, MacColl 2011). Organisms, for example, might modify the environment in ways that either counteract or amplify other drivers of environmental change (Odling-Smee et al. 2003, 2013), meaning that the various mechanisms of niche construction (Fig. 2B) may vary in their likelihood of driving evolutionary responses in a particular environmental setting. Currently, we know little about how selective agents interact across a range of environmental conditions (Wade and Kalisz 1990, MacColl 2011), and this poses a major challenge for predicting the course of adaptive evolution in natural populations (Barrett and Hoekstra 2011). As part of an intensive research effort integrated across disciplines, ecologists can use niche construction theory to better understand the ecological causes of a broad range of evolutionary dynamics.

\section{Measure evolutionary responses to organism-mediated environmental effects: Table 1, Gap II}

Our literature review revealed that many of the more ecologically oriented studies rarely investigate organismmediated environmental effects together with evolutionary responses (Gap II in Table 1). Recent research on the reciprocal interactions between ecological and evolutionary dynamics is increasingly filling this gap (Hairston et al. 2005, Schoener 2011, Becks et al. 2012), but more studies are needed that examine how chemical modifications of the environment by organisms affect the evolution of consumer resource demand (Mizuno and Kawata 2009, Matthews et al. 2011b), and how physical modification of the environment by ecosystem engineers can modify selection gradients of the engineers themselves or of other organisms (Wright et al. 2012).
An interesting example of this gap, and one we will return to later, is that while there is considerable research on organism-mediated transitions between alternative stable states in ecosystems (Scheffer et al. 2001), there is little research quantifying to what extent such states generate contrasting selection pressures and lead to quantifiable differences in evolutionary responses.

\section{Experimentally test more putative mechanisms of niche construction}

In our literature review, studies that explicitly discuss niche construction more often rely on comparative (Beerling 2005, Erwin and Tweedt 2011) than experimental (Donohue et al. 2005, Goddard 2008) evidence to support their arguments (Table 1). For example, the habitat modifying activities of bioturbating species, such as earthworms and bivalves, are consistent with adaptive explanations (Turner 2002, Odling-Smee et al. 2003), and the adaptive radiations following the evolution of bioturbators strongly suggest a macroevolutionary response driven by modifications to soils and sediments (Turner 2002, Meysman et al. 2006, Erwin and Tweedt 2011). However, there is little experimental evidence showing how bioturbation activities can affect selection pressures (Criterion 2) in a way that would affect evolutionary responses (Criterion 3). There are, however, experimental studies that measure changes in selection pressures caused by organism-mediated modifications to the environment, illustrative of the type of research needed to address the second criterion (Wright et al. 2012). In a study on ecosystem engineers, Wright et al. (2012) showed that invasive seaweeds (Caulerpa taxifolia) modify the physical and chemical characteristics of coastal marine sediments, and, in so doing, alter selection gradients on native bivalves (Anadara trapezia). Specifically, the relationships between several morphological traits (e.g., shell length, gill mass, and palp mass) and relative performance (i.e., change in biomass over time) of Anadara trapezia (the recipient of niche construction) differed in the presence and absence of Caulerpa taxifolia (the niche constructor). While this study showed habitat-specific variation in selection gradients, it did not document contrasting evolutionary responses and so does not meet our third criterion. Nevertheless, similar experimental approaches could be expanded upon to test for evolutionary responses of organisms to a broad range of environmental modifications. In the following section, we expand on earlier ideas (OdlingSmee et al. 2003) in order to develop new approaches to comparatively and experimentally test key elements of niche construction theory.

\section{Designing Comparative Tests of Niche Construction Theory}

Many of the archetypical examples used to explain niche construction theory are largely based on compar- 

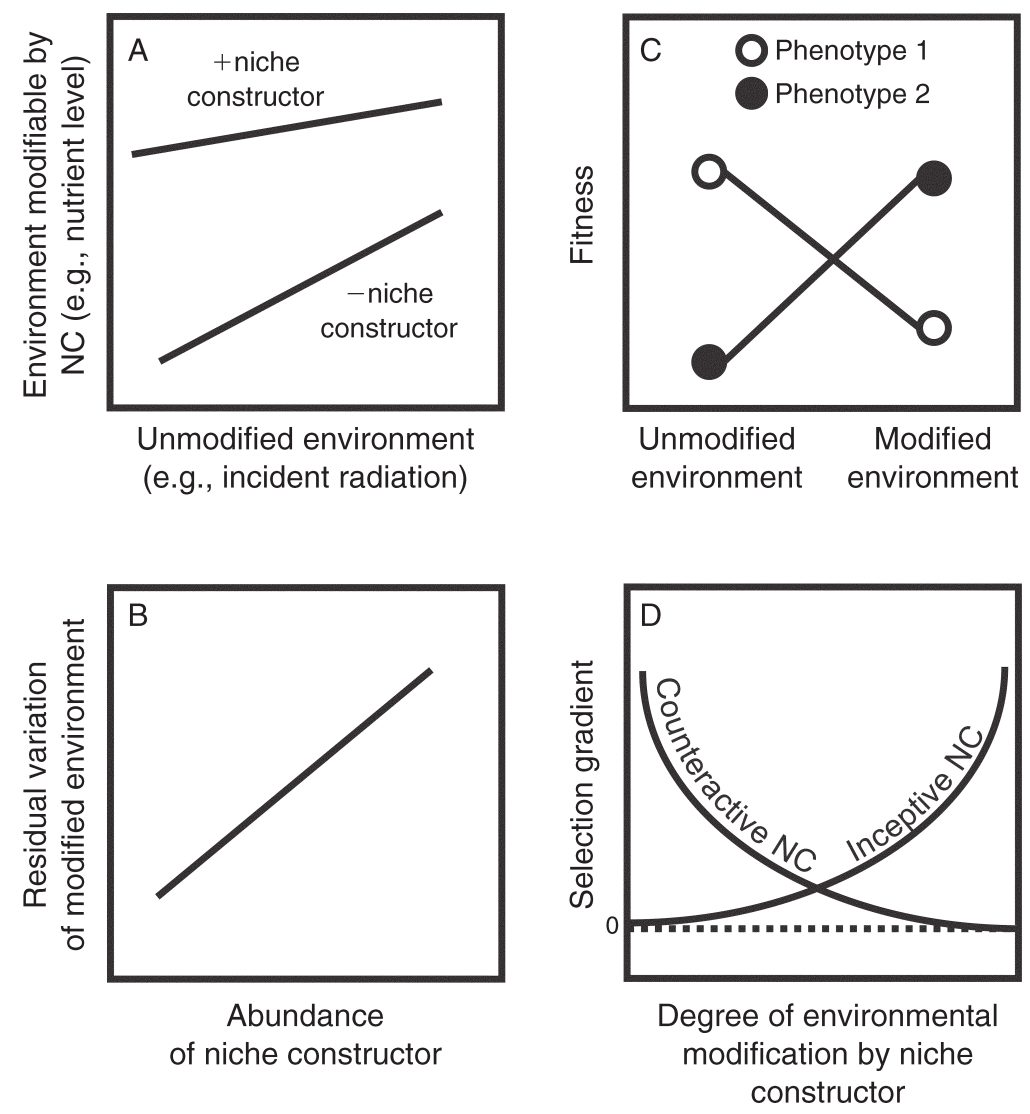

FIG. 3. Four examples of comparative tests of the niche construction (Criteria 1 and 2). (A) Tests for relationships between unmodified and modifiable environmental properties in the presence $(+)$ and absence $(-)$ of a candidate niche constructor (Criteria 1). Differences in such relationships (e.g., line slopes) could be associated with organism-mediated environmental modifications. (B) Tests for the relationship between the abundance of an agent and variation in a modified component of the environment that is unexplained by other environmental conditions (Criteria 1). The indicated relationship could occur if the organism's effects on the modified component of the environment are linearly related with the abundance of the organism. (C) Tests of whether the relative fitness of two organisms with different phenotypes differ between two environments that are either unmodified or modified by a putative niche constructor (Criteria 2). (D) Tests for a relationship (for example among sites) between selection gradients and the degree of environmental modification of a niche constructor (Criteria 2). See Odling-Smee et al. (2003) for a description of counteractive and inceptive niche construction.

ative evidence (Odling-Smee et al. 2003). Here, we summarize some comparative approaches to identify niche construction and test for evolution by niche construction.

\section{Do organism-mediated environmental modifications affect selective environments?}

The environmental effects of organisms are often determined by their biomass and dominance in an ecosystem (Vanni et al. 1997), by their functional role (Jones et al. 1997), and by their phenotype (Schmitz 2010). A comparative study that builds on such ecological work, could gain support for the first criterion by finding contrasting relationships between the unmodifiable and modifiable components of the environment in the presence and absence of a putative niche constructor (Fig. 3A). Further support could come from relationships between the abundance of a niche constructor and unexplained variation in the modifiable component of the environment (Fig. 3B).

To test the second criteria, one could use wellestablished approaches to test how putative selective agents (i.e., environmental modifications) shape the phenotypic distribution of a population. Evidence of selection can be quantified by measuring selection differentials, which are the mean trait differences between the entire population and the subset of individuals that parent the next generation (Endler 1986), and by quantifying selection gradients, which are the slopes of the relationships between relative fitness and a quantitative trait that is expressed in units of standard deviation (Hoekstra et al. 2001). In a comparative study, one can either test for crossing reaction norms of the fitness of a recipient organism in 
habitats with and without a niche constructor (Fig. 3C), or test whether variation in the environmental effects of a putative niche constructor covaries positively or negatively with selection gradients of a recipient population (Fig. 3D).

It is important to note that identifying such associations requires extensive data sets in terms of the number of sampling sites or habitats. In addition, these studies would need to rule out several alternative explanations for associations. These include non-random habitat selection by the niche constructor based specifically on the environmental conditions that it could otherwise modify, and habitat-specific variation in either the carrying capacity of the niche constructor within its potential niche space or in the selective environment favoring certain phenotypes. These alternate explanations can be difficult to eliminate without experimental manipulations.

\section{Does the modified environment by an organism cause an evolutionary response in a recipient?}

To test for evolution by niche construction (Criterion 3 ), one must determine whether an organism-mediated environmental modification acts as an agent of selection and causes an evolutionary response in a recipient species. One potential comparative approach would be to quantify how the rate of evolutionary change of a recipient differs in environments that are either modified or unmodified by a niche constructor. Rates of evolution can be quantified in Haldane units, which measure the change in a mean trait value per generation relative to its standard deviation (Hendry and Kinnison 1999). However, such an approach would also include any phenotypic changes caused by plasticity, and would not satisfy our third criterion that requires a genetic component of evolutionary change. This could be addressed by performing common garden experiments with organisms from the recipient population that have been exposed to the modified and unmodified environments.

In a recent review, Hansen et al. (2012) propose clear criteria for quantifying adaptive genetic responses to specific environmental changes, and these can be adopted to test Criterion 3. In summary, the approach is to (1) demonstrate that suitable genetic variation exists that could respond to a specific environmental modification, (2) test for a genetic change over time consistent with selection, and (3) confirm that the environmental modification caused the observed genetic change within the defined population (Hansen et al. 2012). Indeed, it is not easy to unambiguously show that the environmental modifying activities of organisms affect their own evolutionary trajectory, or that of another recipient population. The most direct way is to test for relationships between allele frequencies or genotypic trait values of a recipient species and the extent of environmental modification caused by the niche constructor (Fig. 4Ci and ii). We are not aware of any studies that have attempted this in the framework of niche construction theory.

\section{Designing Experimental Tests of Niche Construction}

It is not a trivial task to determine whether or not organism-mediated environmental modifications can alter selection pressures and subsequently drive an evolutionary response, and it is likely best addressed by experimental tests (Barrett and Hoekstra 2011, MacColl 2011). In general, it is much easier to measure the strength and form of natural selection (Hoekstra et al. 2001, Siepielski et al. 2009) than to determine the underlying causes (i.e., agents; Wade and Kalisz 1990, MacColl 2011) and eventual outcomes (Barrett and Hoekstra 2011). It is even difficult to identify the agents of selection in nature for well-described polymorphic traits with a known genetic basis (MacColl 2011). The challenge partly stems from interactions among multiple selective agents that can lead to complex fitness landscapes where selection differentials are a function of multiple axes of modifiable or un-modifiable environmental conditions (Wade and Kalisz 1990, MacColl 2011). The most convincing experimental studies are those that manipulate putative agents of selection and measure the consequences for the strength of selection (Barrett and Hoekstra 2011, MacColl 2011). Even more persuasive, and decidedly rare, are experiments that simultaneously manipulate both the agent of selection and the target of selection (Lankau and Strauss 2007). As a first approach, one could carry out targeted experiments in which the biomass or dynamics of a potential niche constructor is manipulated and evolutionary responses are monitored in a recipient population (Odling-Smee et al. 2003). To illustrate this idea, we propose the following series of questions as a guide for future experimental tests of evolution by niche construction.

\section{Question 1: What is the effect-size distribution of organism-mediated environmental effects?}

It is useful to quantify the distribution of organisms' environmental effects (Criterion 1) because niche construction is more likely to occur if such effects are not too weak, too diffuse, or too transient to cause a detectable change in selection. Common gardening experiments (Matthews et al. 2011b) that are conducted in outdoor experimental ecosystems that are either selfcontained (Harmon et al. 2009, Matthews et al. 2011a) or located in situ (Palkovacs and Post 2009) are particularly useful for quantifying the distribution of organisms' environmental effects. Such experiments are designed to investigate how an organism modifies its environment, either relative to the absence of the organism or relative to how another organism modifies the same environment. By analyzing time series of multiple environmental metrics in replicate ecosystems (that start with identical conditions), one can disentangle the environmental effects of a putative niche 
A) Measuring the effect-size distribution of organism-mediated environmental modifications
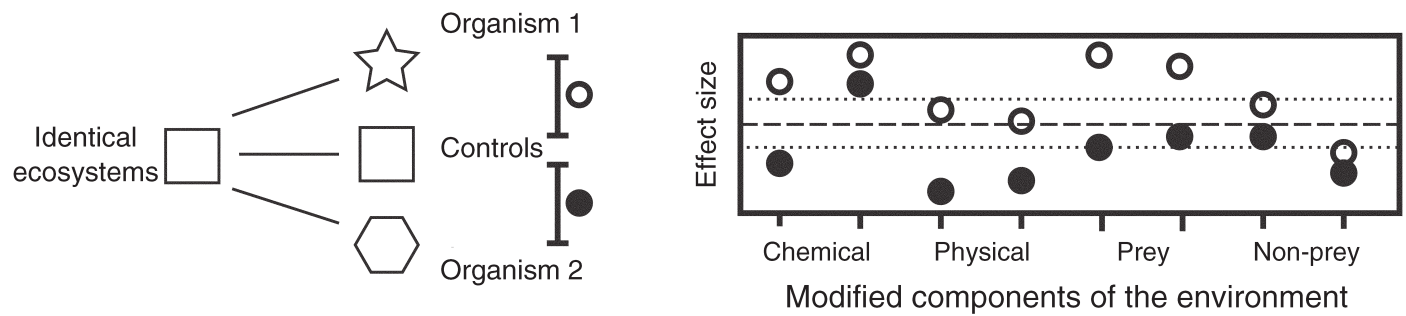

B) Exploring the persistence time of environmental modifications
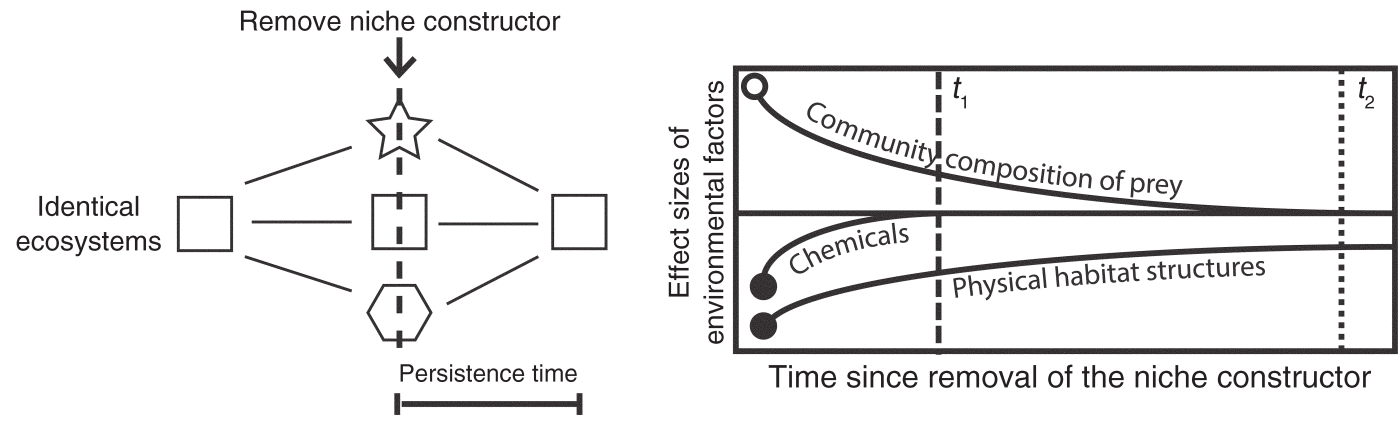

C) Evolutionary responses of recipients ( $y$-axis) caused by niche constructors ( $x$-axis)
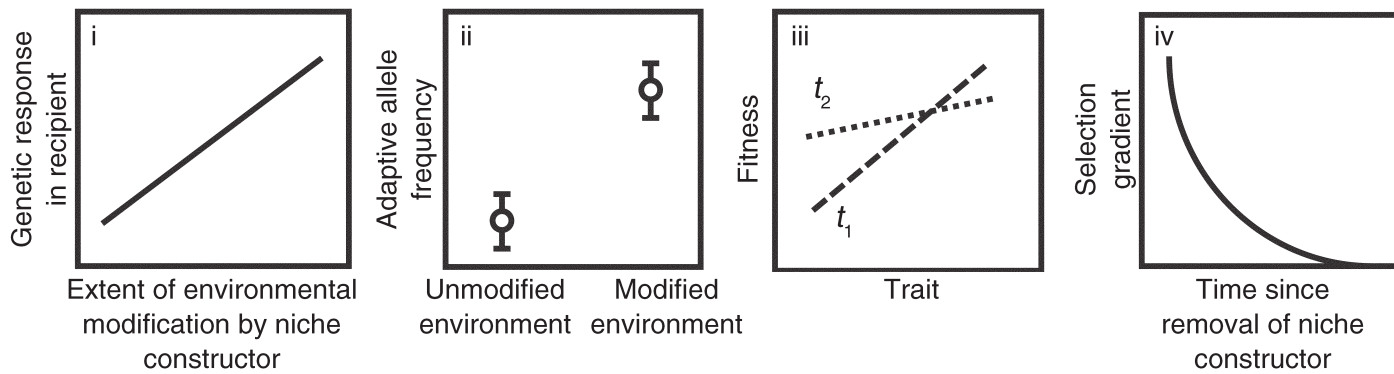

FIG. 4. (A) Experimental design of a common gardening experiment used to measure how potential niche constructors can have contrasting effects on ecosystems (e.g., organism 1 modifies the environment from square to star, while organism 2 modifies the environment from square to hexagon), relative to unmodified ecosystems (i.e., squares). The difference between the modified and the control ecosystems is the effect size for a given ecosystem metric, as shown in the panel on the right. Dotted lines delineate where the effect size is not significantly different from zero (dashed line). (B) Same approach as in panel A, except the ecosystem metrics are measured multiple times (e.g., $\left.t_{1}, t_{2}\right)$ after the organism doing the ecosystem modification is removed. (C) Four different ways to quantify evolutionary changes in common gardening experiments. In panels i and ii, genetic properties of populations or individuals can be measured along a gradient of ecosystem modification, and, following the removal of a potential niche constructor, one can measure how selection gradients (panel iii, times refer to panel B) change through time (panel iv).

constructor from external forcing by temperature, rainfall, or incident radiation (Matthews et al. 2011a). This is possible for experiments in which the organism causing the environmental modification is either present or absent, and in designs where the biomass of the organism is kept constant but its phenotype or genotype varies among treatments (Harmon et al. 2009, Matthews et al. 2011a). A more elaborate experimental design would be to manipulate the niche-constructing activities of an organism, while still keeping the organisms in the system. This might be possible by routinely removing structures created by the organism, or by homogenizing some aspect of the environment that the organism modifies and that is thought to affect selection pressures. 
Such experiments would require a detailed knowledge about both the traits underlying the environmental modification, and about how variation in fitness of the recipient organism is aligned with the modifiable environmental conditions.

Quantifying how organisms differentially affect their environment (e.g., Fig. 4A) might help predict how they shape selection pressures and drive evolutionary responses (Odling-Smee et al. 2003, 2013). One possibility is that organisms may differentially modify multiple axes of environmental variation so as to increase the dimensionality of selection regimes and strengthen divergent selection (Nosil et al. 2009). Another possibility is that organisms narrow the range of environmental conditions experienced by the organism and impose stabilizing selection, which could happen by habitat choice (Donohue et al. 2005) or by physical manipulation of the environment that buffers the evolutionary response of populations to external environmental drivers (Turner 2002, Laland and Brown 2006).

\section{Question 2: How persistent through time} are organism-mediated environmental effects?

The environmental effects of organisms range from trivial modifications that dissipate quickly, to long lasting habitat modifications that persist beyond the lifetime of the organism (Odling-Smee et al. 2003, Hastings et al. 2007, Jones 2012). Persistence time can be measured in a simple common gardening experiment by extending the design proposed in Fig. $4 \mathrm{~A}$ to include a phase in which the niche constructor is removed (Fig. 4B). Upon removal of the niche constructor, persistence time is the interval over which one can statistically differentiate the modified and unmodified ecosystems (Fig. 4B). This metric is analogous to quantifying the rate of ecosystem recovery to a pulsed stressor (i.e., a putative niche constructor), which is often measured in experimental tests of ecosystem resilience (Cottingham and Carpenter 1994). Persistence is closely related to the concept of ecological inheritance (Odling-Smee et al. 2003), which posits that organisms not only transmit genes to subsequent generations, but also leave a legacy of environmental modification that can affect selective pressures beyond their own lifetime. Ecosystem engineers, for example, can affect environments over a very broad range of spatial and temporal scales (Hastings et al. 2007), allowing ample opportunity for evolutionary effects to occur. We are unaware of any experimental tests of how the ecosystem engineering activities of organisms can alter selection pressures and drive evolutionary responses.

\section{Question 3: Do modifiable components of the environment} affect selection pressures and evolutionary responses?

Both selection experiments and experimental evolution trials are useful to test how organism-mediated environmental modifications might influence the environmental sources of selection and drive evolutionary responses (Barrett and Hoekstra 2011, MacColl 2011). Selection experiments can test whether heritable phenotypic changes within a population are caused by a particular environmental modification, and are well suited for testing Criterion 2. Experimental evolution trials performed over one or more generations can test for evolutionary responses to selection, and are well suited for testing Criterion 3. Designing robust experiments to test Criteria 2 and 3 is not trivial, because it requires that the ecosystem modification caused by the niche constructor is the reason for a particular evolutionary response.

One robust experimental approach for testing Criterion 2 and 3, is to do a common gardening experiment, with treatments that manipulate either the abundance or modifying activities of a niche constructor, followed by either a selection experiment (Criterion 2) or an experimental evolution trial (Criterion 3) within the same set of experimental ecosystems. The common gardening experiment would reveal the effect size distribution of organism-mediated environmental modifications (Fig. 4A). The selection phase of the experiment would specifically test for niche construction, and reveal whether selection pressures on a recipient organism differed among treatments in the common gardening phase (Fig. 4C). Alternatively (or additionally), an experimental evolution trial could be performed in the modified environment in order to assess if evolutionary responses in a recipient population differed among treatments, providing evidence that niche construction led to alternative evolutionary outcomes (Fig. 4C). In practice, working with relatively isolated and controlled ecosystems (e.g., mesocosms) affords the opportunity to monitor evolutionary changes in recipient populations over time.

A potentially more practical approach for testing criteria 2 and 3 , is to experimentally manipulate environmental factors that are known to be modifiable by a putative niche constructor (e.g., emulate the physical conditions affected by an engineer) and perform selection experiments and experimental evolution trials under these manipulated conditions. For example, there is experimental evidence that Trinidadian guppies adapted to different predation regimes (Reznick and Endler 1982) can alter the flux of nutrients in streams and have different effects on algal growth (Palkovacs and Post 2009, Bassar et al. 2010, 2012). Odling-Smee et al. (2013) hypothesized that changes in algal biomass might alter the distribution of dietary algal pigments that influence the coloration of male guppies, which can subsequently affect either sexual selection or predator mediated selection pressures. In order to test specific effect pathways in this system, one could mimic the contrasting environmental effect of locally adapted guppies by manipulating the level of nutrients in the system. Such an approach is eminently more feasible than common gardening experiments in which variation in the density, genotype or phenotype of 
the putative niche constructor (e.g., guppies) is used to modify the environment directly (see Fig. 4A). One drawback, however, is that the experimentally modified environments may lack realism and not reflect the subtleties of the modifying activities of the niche constructor. Indeed, the foraging activities of organisms can shape community composition and ecosystem properties in ways that might not be reproducible by direct manipulation (Vanni et al. 1997, Schmitz 2010). In some cases, ecosystem engineers can shape the geometry of their physical environment in complex ways that might be impossible to recreate by experimental manipulation (Jones 2012), but in other cases the effects of engineers on physical habitat structure can be mimicked in an experimental setting (Crooks and Khim 1999, Lill and Marquis 2003). Regardless, using artificially modified environments to mimic the effect of a selective agent might lead to associations between fitness and phenotype that do not reflect a realistic set of environmental conditions. For this same reason, many laboratory manipulations of selection pressures have led to misleading conclusions about the associations between genotype, phenotype, and fitness (Barrett and Hoekstra 2011).

Another complication with testing the third criterion is the need to demonstrate an evolutionary response in a recipient population using a natural range of phenotypic and genetic variation. Ideally, one should work with the standing genetic variation that is present in a population of a recipient. This stringent condition is justified by the prevalence of genotype $\times$ environment interactions and genotype $\times$ genotype $\times$ environment interactions (Barrett and Hoekstra 2011). Careful consideration of the genetic background of the recipient is a critical step in both selection experiments and experimental evolution trials, because putative adaptive alleles in one genetic background can produce different fitness effects in another genetic background and fundamentally change selection coefficients. Furthermore, epistatic interactions between genes can differ among populations, and the environmental conditions in which they evolve might influence the relationship between phenotype and fitness in a novel environment (Barrett and Hoekstra 2011).

Overall, testing the wide range of potential niche construction mechanisms is best achieved by an integrative research effort that combines comparative and experimental approaches. In the following section we outline a model system for testing niche construction theory that has been extensively studied by aquatic ecologists but has received comparably little attention from evolutionary biologists.

\section{A Case Study: Alternative Stable States in Shallow Lake Ecosystems}

The presence of alternate stable states is the main explanation for sudden and dramatic shifts observed in terrestrial, marine, and inland water ecosystems (Scheffer et al. 2001). Considerable research has been directed towards understanding the mechanistic basis of tipping points between states (Scheffer and Carpenter 2003, Carpenter et al. 2011). Shifts in ecosystem state often occur because a specific group of organisms that has a stabilizing effect on environmental conditions (e.g., trees on microclimate in a forest) is overwhelmed by some environmental stressor (e.g., drought, exploitation), leading to dramatic changes in both community composition and environmental conditions. Here, we use one of the best-studied regime shifts, namely that between the turbid and clear-water state in shallow lakes (Scheffer and Carpenter 2003), to illustrate the existing evidence for niche construction and exciting avenues for future research.

Organisms in shallow lakes modify the abiotic and biotic environment in multiple ways that can influence the transition between stable states (i.e., clear and turbid states). Macrophytes, for example (Fig. 5), act as ecosystem engineers in shallow lakes because their roots stabilize sediments and reduce phosphorus recycling to phytoplankton, and their canopies reduce turbulent mixing and attenuate light availability (Byers et al. 2006). There is both comparative (Scheffer et al. 2001) and experimental (Declerck et al. 2007) evidence for the strong impact of macrophytes on the relationship between phosphorus concentration and phytoplankton biomass (paralleling Fig. 3A), and, as a result, in the maintenance of the clear water state. Macrophytes can also affect the transition between different states in shallow lakes by modifying trophic interactions (Byers et al. 2006). In shallow lakes and ponds, omnivorous fish can dramatically modify the environment by uprooting macrophytes, resuspending sediments, and increasing turbidity levels (Drenner et al. 1998). More generally, there is overwhelming comparative (Jeppesen et al. 1997) and compelling experimental evidence (Carpenter and Kitchell 1993, Vanni et al. 1997) that fish in aquatic systems have important impacts on prey community composition and size structure, particularly through their effects on large bodied cladocerans that play a pivotal role in the cascading trophic interactions that influence phytoplankton abundance (Carpenter and Kitchell 1993). Mesocosm studies have demonstrated that the presence of the large-bodied cladoceran Daphnia magna can have a significant impact on the community composition of phyto- and bacterioplankton (Verreydt et al. 2012), and that the genotype of Daphnia magna can impact the community composition of zooplankton (De Meester et al. 2007).

Despite a plethora of evidence for the effects of organisms on the environmental conditions of shallow lakes, so far no studies have specifically tested for evolution by niche construction. Macrophytes are good candidates for being niche constructors because of their strong impacts on the abiotic and biotic conditions of shallow-lake ecosystems and their central role in mediating the transition between alternative stable states. In particular, there are many potential ways that 


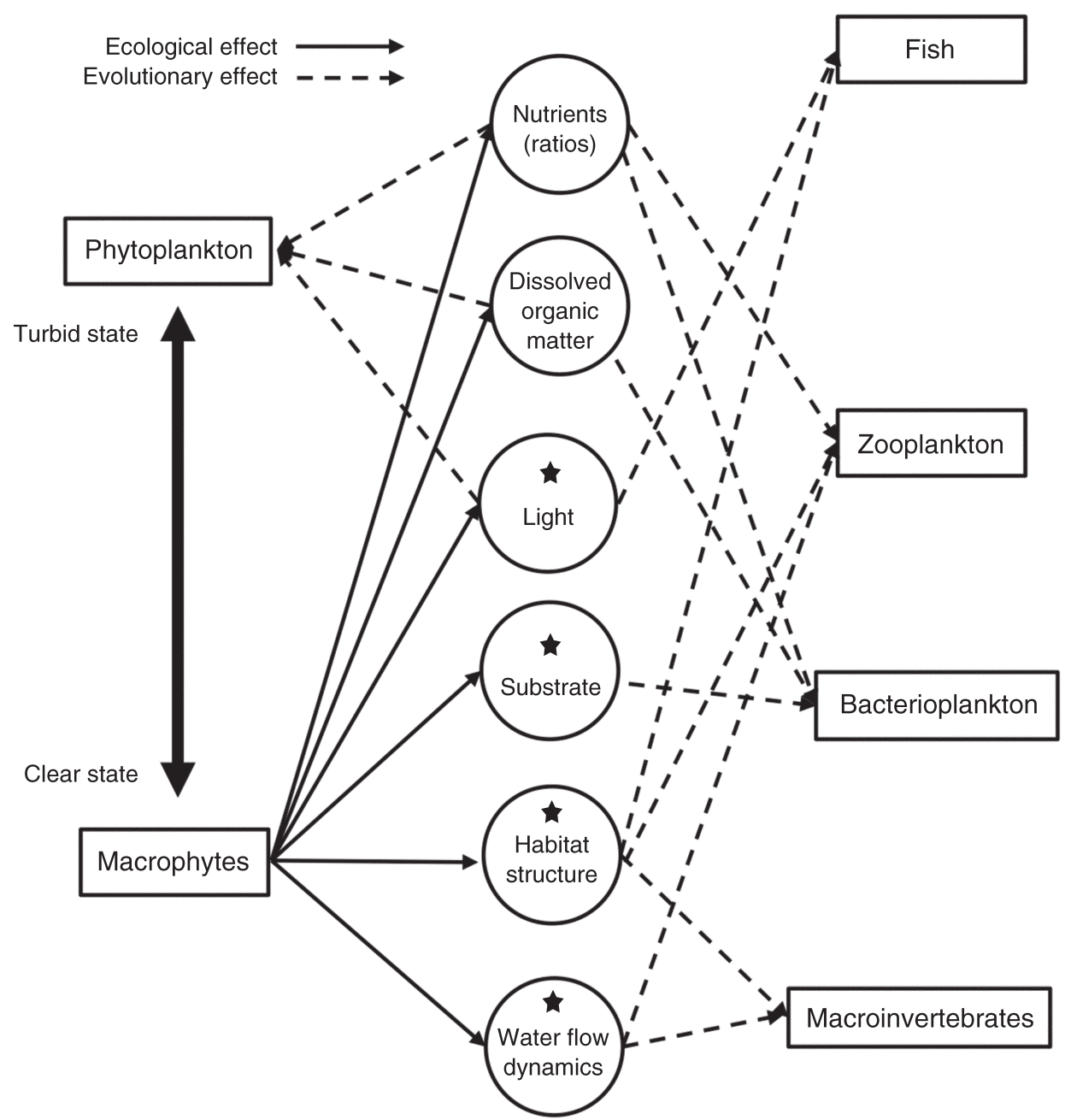

FIG. 5. A schematic emphasizing how macrophyte communities can have non-evolutionary effects (shown as solid arrows) on the abiotic environment (circles) of shallow lakes in general, and on the physical (indicated by stars) and chemical conditions in particular. Such effects could lead to both evolutionary effects (shown as dashed arrows) and ecological effects (arrows not shown for clarity but follow the same paths as evolutionary effects) on organisms (circles) that play a role in the transition between turbid and clear states (shown as a double-headed arrow). Following Fig. 1, macrophytes could drive evolution by niche construction by a variety of mechanisms in shallow lakes. Such evidence could come from pathways of effect that start with macrophytes, pass through an abiotic environmental condition, and end with an evolutionary effect on a recipient organism. Ecological and evolutionary effects between organisms (e.g., trophic interactions) are also left out for clarity, but are also very important for understanding transitions between stable states in shallow lakes.

macrophytes might influence evolutionary responses through their modification of abiotic conditions (Fig. 5). For example, macrophytes might cause evolutionary responses in phytoplankton by directly manipulating the light and nutrient environment of shallow lakes (Collins and Bell 2004, Stomp et al. 2004), or, alternatively, by providing habitat for zooplankton communities that graze on phytoplankton. Differences in grazing pressure might explain the genetic differentiation in the size and number of cells in colonies of the planktonic alga Desmodesmus armatus isolated from a neighboring turbid and clear-water system (Vanormelingen et al. 2009). Macrophytes can also provide refugia for prey species that are vulnerable to visually foraging preda- tors. In recent work combining paleolimnology with quantitative genetics, where organisms can be resurrected from resting stages preserved in lake sediments, there is evidence for the adaptation of Daphnia phototactic behavior in response to changes in fish predation pressure (Cousyn et al. 2001). Similarly, the genetic adaptation in pigmentation of Asellus aquaticus, a common freshwater crustacean of shallow lakes, might be explained by a combined response to macrophytemediated changes to habitat structure, light environments, and predation pressure (Hargeby et al. 2005). While Fig. 5 is not exhaustive, it highlights the potential for one prominent group of organisms (i.e., macro- 
phytes) to cause evolutionary effects by altering abiotic conditions of shallow-lake ecosystems.

There are well-established experimental designs to test for the presence of alternative stable states (Schröder et al. 2005), and combining these with selection experiments and experimental evolution trials (e.g., Fig. 4) would help uncover the specific mechanisms underlying how species interactions and organism-mediated changes to shallow-lake ecosystems can influence selection pressures and drive evolutionary responses. In particular, such research might offer new insights into which modifications to the abiotic environment might persist and influence selection pressures through time (i.e., ecological inheritance), and where such effects might lead to evolutionary responses (i.e., evolution by niche construction). In aquatic mesocosms, one could use a common gardening experiment to establish alternate stable states in replicated experimental mesocosms by directly manipulating macrophytes, nutrients, and fish. To test Criterion 2, one could measure selection gradients of a target organism inhabiting both ecosystem states. To test Criterion 3, one could track changes in the phenotype and genotype of short-lived organisms (e.g., phytoplankton) through time in both clear and turbid states. To perform experiments at a larger scale, one could also capitalize on whole-lake manipulations where fish are removed in order to create opportunities for the establishment of macrophytes. In such cases, one could monitor evolutionary responses of organisms at different trophic levels over time. In sum, shallow lakes offer a model system with many uncharted dimensions to explore in the context of niche construction. A fundamental question to address is how evolution by niche construction might stabilize or destabilize equilibrium states in systems that show regime shifts.

\section{Back to Nature: Some Further Challenges}

While experimental approaches allow for strong tests of certain aspects of niche construction theory, it remains a monumental challenge to identify the importance of evolution by niche construction in nature. One can make progress by building on existing studies of keystone species, ecosystem engineers, and the newly emerging model systems in eco-evolutionary dynamics, but there are numerous complexities to consider. At the level of niche constructors, environmental modifications that influence selection might be driven by the combined action of multiple species, rather than any single species. Here, we only consider niche construction to operate if the environmental modification leading to altered selection pressures is attributable to particular organisms. At the level of the recipients of niche construction, it is possible that there are no species with the evolutionary potential to respond to organism-modified environmental conditions (Vincent and Brown 2005) or that an ecological response will preempt any evolutionary responses (Urban et al. 2008). This latter point highlights an important conceptual link between niche construction and evolving metacommunities (Urban et al. 2008). Following an organism-mediated change to the environment, a community may change its average trait values (e.g., body size) by a combination of changes in the relative abundance of species (cf. species sorting) and evolutionary changes in the species that make up the community (Urban et al. 2008). Evolution by niche construction is only present if the latter outcome occurs.

We believe that the testing of niche construction theory is still in its infancy and that the approaches we advocate will lead to greater integration among related disciplines (Fig. 1). There are ample examples in which species modify the environment, and where environmental change alters selection pressures and induces evolutionary responses in focal species, but only a handful of studies that show all of these aspects in the same system, and even fewer that test a mechanistic link between evolutionary responses and the environmental modifying activities of organisms. There are numerous descriptive cases of niche construction and some intriguing experimental tests (e.g., Table 1), but there are many plausible mechanisms of environmental modification (Fig. 2) and numerous organisms that could act as putative niche constructors and recipients of niche construction (Table 1). Intriguingly, there are also numerous well-developed model systems that provide exciting avenues for both evolutionary biologists and ecologists to explore niche construction dynamics. Indeed, we are well poised to elucidate the network of interactions between niche constructors and their environment, and to assess the importance of niche construction in explaining ecological and evolutionary changes in nature.

\section{ACKNOWLEDGMENTS}

This paper is a product of the Working Group "Ecosystem Engineering and Evolution" convened at the Centre for Estuarine and Marine Ecology, Netherlands Institute of Ecology (NIOO), Yerseke, The Netherlands. Workshops were organized by Tjeerd Bouma, Clive Jones, and Peter Herman and financially supported by KNAW grant ISK/6445/VPP and the NIOO. We thank Joke van Houte, Anneke van der Endt, Elly van Hulsteijn, Christine van der Jagt, Laura Wisse, and Jan Megens for logistical support of the workshops. We also thank Laurent Lehmann, Monique de Jager, Peter Herman, and Carlos Melian for useful discussions and comments on the manuscript. We particularly thank Kevin Laland for helping us revise the manuscript. C. G. Jones thanks The Royal Netherlands Academy for Arts and Sciences and The Cary Institute of Ecosystem Studies for financial support. Contribution to the program of the Cary Institute of Ecosystem Studies. B. Matthews was supported by SNF grant number 31003A125006, and L. De Meester by KU Leuven Research Fund Excellence Center PF/2010/007. All co-authors participated in the working group discussions, and contributed to subsequent discussions about the manuscript. B. Matthews wrote most of the first draft of the manuscript. L. De Meester wrote several sections of the manuscript and made substantial contributions to the structure, concepts, and revisions of all manuscript drafts. B. W. Ibelings, V. Nuutinen, T. Bouma, and J. van de Koppel contributed substantially to revisions of the 
manuscript. J. Odling-Smee and C. G. Jones made substantial contributions to the structure, concepts, and revisions of all manuscript drafts, and C. G. Jones and T. Bouma organized, and $\mathrm{C}$. G. Jones chaired the working group.

\section{Literature Cited}

Bailey, R., K. Schönrogge, J. Cook, and G. Melika. 2009. Host niches and defensive extended phenotypes structure parasitoid wasp communities. PLoS Biology 7:e1000179.

Barrett, R. D. H., and H. E. Hoekstra. 2011. Molecular spandrels: tests of adaptation at the genetic level. Nature Reviews Genetics 12:767-780.

Bassar, R. D., R. Ferriere, A. López-Sepulcre, M. C. Marshall, J. Travis, C. M. Pringle, and D. N. Reznick. 2012. Direct and indirect ecosystem effects of evolutionary adaptation in the Trinidadian guppy (Poecilia reticulata). American Naturalist 180:167-185.

Bassar, R. D., et al. 2010. Local adaptation in Trinidadian guppies alters ecosystem processes. Proceedings of the National Academy of Sciences USA 107:3616-3621.

Becks, L., S. P. Ellner, L. E. Jones, and J. N. G. Hairston. 2012. The functional genomics of an eco-evolutionary feedback loop: linking gene expression, trait evolution, and community dynamics. Ecology Letters 15:492-501.

Beerling, D. 2005. Leaf evolution: gases, genes and geochemistry. Annals of Botany 96.

Benkman, C. W., T. L. Parchman, and E. T. Mezquida. 2010. Patterns of coevolution in the adaptive radiation of crossbills. Annals of the New York Academy of Science 1206:1-16.

Bonduriansky, R. 2012. Rethinking heredity, again. Trends in Ecology and Evolution 27:330-336.

Bonduriansky, R., and T. Day. 2009. Nongenetic inheritance and its evolutionary implications. Annual Review of Ecology and Systematics 40:103-125.

Boogert, N., D. Paterson, and K. Laland. 2006. The implications of niche construction and ecosystem engineering for conservation biology. BioScience 56:570.

Bouma, T. J., M. B. De Vries, and P. M. J. Herman. 2010. Comparing ecosystem engineering efficiency of two plant species with contrasting growth strategies. Ecology 91:26962704.

Brodie, E. III. 2005. Caution: niche construction ahead. Evolution 59:249-251.

Byers, J. E., K. Cuddington, C. G. Jones, T. S. Talley, A. Hastings, J. G. Lambrinos, J. A. Crooks, and W. G. Wilson. 2006. Using ecosystem engineers to restore ecological systems. Trends in Ecology and Evolution 21:493-500.

Carpenter, S., and J. Kitchell. 1993. The trophic cascade in lakes. Cambridge University Press, Cambridge, UK.

Carpenter, S. R., et al. 2011. Early warnings of regime shifts: a whole-ecosystem experiment. Science 332:1079-1082.

Chase, J. M., E. G. Biro, W. A. Ryberg, and K. G. Smith. 2009. Predators temper the relative importance of stochastic processes in the assembly of prey metacommunities. Ecology Letters 12:1210-1218.

Collins, S., and G. Bell. 2004. Phenotypic consequences of 1,000 generations of selection at elevated $\mathrm{CO} 2$ in a green alga. Nature 431:566-569.

Corenblit, D., J. Steiger, A. Gurnell, and R. J. Naiman. 2009. Plants intertwine fluvial landform dynamics with ecological succession and natural selection: a niche construction perspective for riparian systems. Global Ecology and Biogeography 18:507-520.

Cottingham, K., and S. Carpenter. 1994. Predictive indexes of ecosystem resilience in models of north temperate lakes. Ecology 75:2127-2138.

Cousyn, C., L. De Meester, J. K. Colbourne, L. Brendonck, D. Verschuren, and F. Volckaert. 2001. Rapid, local adaptation of zooplankton behavior to changes in predation pressure in the absence of neutral genetic changes. Proceedings of the National Academy of Sciences USA 98:6256-6260.

Crespi, B. 2004. Vicious circles: positive feedback in major evolutionary and ecological transitions. Trends in Ecology and Evolution 19:627-633.

Crooks, J. A., and H. S. Khim. 1999. Architectural vs. biological effects of a habitat-altering, exotic mussel, Musculista senhousia. Journal of Experimental Marine Biology and Ecology 240:53-75.

Danchin, É., A. Charmantier, F. A. Champagne, A. Mesoudi, B. Pujol, and S. Blanchet. 2011. Beyond DNA: integrating inclusive inheritance into an extended theory of evolution. Nature Reviews Genetics 12:475-486.

Dawkins, R. 1982. The extended phenotype. Oxford University Press, New York, New York, USA.

Dawkins, R. 2004. Extended phenotype-but not too extended. A reply to Laland, Turner and Jablonka. Biology and Philosophy 19:377-396.

De Meester, L., G. Louette, C. Duvivier, C. Van Damme, and E. Michels. 2007. Genetic composition of resident populations influences establishment success of immigrant species. Oecologia 153:431-440.

Declerck, S., M. Vanderstukken, A. Pals, K. Muylaert, and L. De Meester. 2007. Plankton biodiversity along a gradient of productivity and its mediation by macrophytes. Ecology 88:2199-2210.

Dickman, E. M., J. M. Newell, M. J. González, and M. J. Vanni. 2008. Light, nutrients, and food-chain length constrain planktonic energy transfer efficiency across multiple trophic levels. Proceedings of the National Academy of Sciences USA 105:18408-18412.

Donohue, K., C. R. Polisetty, and N. J. Wender. 2005. Genetic basis and consequences of niche construction: plasticity induced genetic constraints on the evolution of seed dispersal in Arabidopsis thaliana. American Naturalist 165:537-550.

Drenner, R. W., K. L. Gallo, and R. M. Baca. 1998. Synergistic effects of nutrient loading and omnivorous fish on phytoplankton biomass. Canadian Journal of Fisheries and Aquatic Sciences 55:2087-2096.

Ellers, J., E. T. Kiers, C. Currie, and B. McDonald. 2012. Ecological interactions drive evolutionary loss of traits. Ecology Letters 15:1071-1082.

Ellner, S. P., M. A. Geber, and J. N. G. Hairston. 2011. Does rapid evolution matter? Measuring the rate of contemporary evolution and its impacts on ecological dynamics. Ecology Letters 14:603-614.

Endler, J. 1986. Natural selection in the wild. Princeton University Press, Princeton, New Jersey, USA.

Erwin, D. H. 2008. Macroevolution of ecosystem engineering, niche construction and diversity. Trends in Ecology and Evolution 23:304-310.

Erwin, D., and S. Tweedt. 2011. Ecological drivers of the Ediacaran-Cambrian diversification of Metazoa. Evolutionary Ecology 26:417-433.

Fisher, R. A. 1930. The genetical theory of natural selection. Clarendon Press, Oxford, UK.

Flack, J. C., M. Girvan, F. B. M. de Waal, and D. C. Krakauer. 2006. Policing stabilizes construction of social niches in primates. Nature 439:426-429.

Forbes, A., T. Powell, L. Stelinski, and J. Smith. 2009. Sequential sympatric speciation across trophic levels. Science 323:776-779.

Frank, S. A. 2009. Natural selection maximizes Fisher information. Journal of Evolutionary Biology 22:231-244.

Fussmann, G. F., M. Loreau, and P. A. Abrams. 2007. Ecoevolutionary dynamics of communities and ecosystems. Functional Ecology 21:465-477.

Goddard, M. R. 2008. Quantifying the complexities of Saccharomyces cerevisiae's ecosystem engineering via fermentation. Ecology 89:2077-2082. 
Goodman, B. A., and P. T. J. Johnson. 2011. Disease and the extended phenotype: parasites control host performance and survival through induced changes in body plan. PLoS ONE 6:e20193.

Grant, P., and B. Grant. 2006. Evolution of character displacement in Darwin's finches. Science 313:224-226.

Hairston, J. N. G., S. P. Ellner, M. A. Geber, T. Yoshida, and J. A. Fox. 2005. Rapid evolution and the convergence of ecological and evolutionary time. Ecology Letters 8:11141127.

Haloin, J. R., and S. Y. Strauss. 2008. Interplay between ecological communities and evolution. Annals of the New York Academy of Sciences 1133:87-125.

Hansen, M. M., I. Olivieri, D. M. Waller, E. E. Nielsen, and GeM Working Group. 2012. Monitoring adaptive genetic responses to environmental change. Molecular Ecology 21:1311-1329.

Hargeby, A., J. Stoltz, and J. Johansson. 2005. Locally differentiated cryptic pigmentation in the freshwater isopod Asellus aquaticus. Journal of Evolutionary Biology 18:713721.

Harmon, L. J., B. Matthews, S. Des Roches, J. M. Chase, J. B. Shurin, and D. Schluter. 2009. Evolutionary diversification in stickleback affects ecosystem functioning. Nature 458:1167-1170.

Hastings, A., J. E. Byers, J. A. Crooks, K. Cuddington, C. G. Jones, J. G. Lambrinos, T. S. Talley, and W. G. Wilson. 2007. Ecosystem engineering in space and time. Ecology Letters 10:153-164.

Hendrix, P. F. 2006. Biological invasions belowgroundearthworms as invasive species. Springer Netherlands, Dordrecht, The Netherlands.

Hendry, A., and M. Kinnison. 1999. Perspective: the pace of modern life. Measuring rates of contemporary microevolution. Evolution 53:1637-1653.

Hoekstra, H. E., J. M. Hoekstra, D. Berrigan, S. N. Vignieri, A. Hoang, C. E. Hill, P. Beerli, and J. G. Kingsolver. 2001. Strength and tempo of directional selection in the wild. Proceedings of the National Academy of Sciences USA 98:9157-9160.

Holt, R., and J. H. Lawton. 1994. The ecological consequences of shared natural enemies. Annual Review of Ecology and Systematics 25:495-520.

Hoover, J. P., and S. K. Robinson. 2007. Retaliatory mafia behavior by a parasitic cowbird favors host acceptance of parasitic eggs. Proceedings of the National Academy of Sciences USA 104:4479-4483.

Hoover, K., M. Grove, M. Gardner, D. P. Hughes, J. McNeil, and J. Slavicek. 2011. A gene for an extended phenotype. Science 333:1401.

Jeppesen, E., J. P. Jensen, M. Sondergaard, T. Lauridsen, L. Pedersen, and L. Jensen. 1997. Top-down control in freshwater lakes: the role of nutrient state, submerged macrophytes and water depth. Hydrobiologia 342:151-164.

Jones, C. G. 2012. Ecosystem engineers and geomorphological signatures in landscapes. Geomorphology 157-158:75-87.

Jones, C. G., J. H. Lawton, and M. Shachak. 1994. Organisms as ecosystem engineers. Oikos 69:373-386.

Jones, C. G., J. H. Lawton, and M. Shachak. 1997. Positive and negative effects of organisms as physical ecosystem engineers. Ecology 78:1946-1957.

Kerr, B., D. W. Schwilk, and A. Bergman. 1999. Rekindling an old flame: a haploid model for the evolution and impact of flammability in resprouting plants. Evolutionary Ecology $1: 807-833$.

Kokko, H., and A. López-Sepulcre. 2007. The ecogenetic link between demography and evolution: can we bridge the gap between theory and data? Ecology Letters 10:773-782.

Krakauer, D. C., K. M. Page, and D. H. Erwin. 2009. Diversity, dilemmas, and monopolies of niche construction. American Naturalist 173:26-40.
Kylafis, G., and M. Loreau. 2008. Ecological and evolutionary consequences of niche construction for its agent. Ecology Letters 11:1072-1081.

Kylafis, G., and M. Loreau. 2011. Niche construction in the light of niche theory. Ecology Letters 14:82-90.

Lafferty, K. D., et al. 2008. Parasites in food webs: the ultimate missing links. Ecology Letters 11:533-546.

Laland, K., and N. J. Boogert. 2010. Niche construction, coevolution and biodiversity. Ecological Economics 69:731736.

Laland, K. N., and G. R. Brown. 2006. Niche construction, human behavior, and the adaptive-lag hypothesis. Evolutionary Anthropology 15:95-104.

Laland, K. N., and K. Sterelny. 2006. Seven reasons (not) to neglect niche construction. Evolution 60:1751-1762.

Lankau, R. A., and S. Y. Strauss. 2007. Mutual feedbacks maintain both genetic and species diversity in a plant community. Science 317:1561-1563.

Lehmann, L. 2008. The adaptive dynamics of niche constructing traits in spatially subdivided populations: evolving posthumous extended phenotypes. Evolution 62:549-566.

Lewontin, R. C. 1983. Gene, organism, and environment. Pages 273-285 in D. S. Bendall, editor. Evolution from molecules to men. Cambridge University Press, Cambridge, UK.

Lill, J. T., and R. J. Marquis. 2003. Ecosystem engineering by caterpillars increases insect herbivore diversity on white oak. Ecology 84:682-690.

Loreau, M. 2010. From populations to ecosystems: theoretical foundations for a new ecological synthesis. Monographs in population biology. Princeton University Press, Princeton, New Jersey, USA.

Losos, J. B. 2010. Adaptive radiation, ecological opportunity, and evolutionary determinism. American Naturalist 175:623-639.

MacColl, A. D. C. 2011. The ecological causes of evolution. Trends in Ecology and Evolution 26:514-522.

Matthews, B., S. Hausch, C. Winter, and C. Suttle. $2011 a$. Contrasting ecosystem-effects of morphologically similar copepods. PLoS ONE 6:e26700.

Matthews, B., et al. 2011b. Toward an integration of evolutionary biology and ecosystem science. Ecology Letters 14:690-701.

McIntyre, P. B., A. S. Flecker, M. J. Vanni, J. M. Hood, B. W. Taylor, and S. A. Thomas. 2008. Fish distributions and nutrient cycling in streams: Can fish create biogeochemical hotspots? Ecology 89:2335-2346.

Meysman, F., J. J. Middelburg, and C. H. R. Heip. 2006. Bioturbation: a fresh look at Darwin's last idea. Trends in Ecology and Evolution 21:688-695.

Mizuno, A. N., and M. Kawata. 2009. The effects of the evolution of stoichiometry-related traits on population dynamics in plankton communities. Journal of Theoretical Biology 259:209-218.

Morran, L. T., O. G. Schmidt, I. A. Gelarden, R. C. I. Parrish, and C. M. Lively. 2011. Running with the Red Queen: hostparasite coevolution selects for biparental sex. Science 333:216-218.

Mueller, U. G., and N. Gerardo. 2002. Fungus-farming insects: multiple origins and diverse evolutionary histories. Proceedings of the National Academy of Sciences USA 99:15247-15249.

Nosil, P. 2012. Ecological speciation. Oxford University Press, Oxford, UK.

Nosil, P., L. J. Harmon, and O. Seehausen. 2009. Ecological explanations for (incomplete) speciation. Trends in Ecology and Evolution 24:145-156.

Odling-Smee, F. J., K. N. Laland, and M. W. Feldman. 1996. Niche construction. American Naturalist 147:641-648. 
Odling-Smee, F., K. Laland, and M. Feldman. 2003. Niche construction: the neglected process in evolution. Princeton University Press, Princeton, New Jersey, UK.

Odling-Smee, J., D. H. Erwin, E. P. Palcovacs, M. W. Feldman, and K. N. Laland. 2013. Niche construction theory: a practical guide for ecologists. Quarterly Review of Biology 88:4-28.

Okasha, S. 2005. On niche construction and extended evolutionary theory. Biology and Philosophy 20:1-10.

Olff, H., D. Alonso, M. P. Berg, B. K. Eriksson, M. Loreau, T. Piersma, and N. Rooney. 2009. Parallel ecological networks in ecosystems. Philosophical Transactions of the Royal Society B 364:1755-1779.

Palkovacs, E., and D. Post. 2008. Eco-evolutionary interactions between predators and prey: can predator-induced changes to prey communities feed back to shape predator foraging traits? Evolutionary Ecology Research 10:699-720.

Palkovacs, E. P., and D. M. Post. 2009. Experimental evidence that phenotypic divergence in predators drives community divergence in prey. Ecology 90:300-305.

Pearce, T. 2011. Ecosystem engineering, experiment, and evolution. Biology and Philosophy 26:793-812.

Post, D. M., and E. P. Palkovacs. 2009. Eco-evolutionary feedbacks in community and ecosystem ecology: interactions between the ecological theatre and the evolutionary play. Philosophical Transactions of the Royal Society B 364:1629-1640.

Reznick, D., and J. A. Endler. 1982. The impact of predation on life history evolution in Trinidadian guppies (Poecilia Reticulata). Evolution 36:160-177.

Roughgarden, J. 1976. Resource partitioning among competing species - a coevolutionary approach. Theoretical Population Biology 9:388-424.

Scheffer, M., and S. R. Carpenter. 2003. Catastrophic regime shifts in ecosystems: linking theory to observation. Trends in Ecology and Evolution 18:648-656.

Scheffer, M., S. Carpenter, J. A. Foley, C. Folke, and B. Walker. 2001. Catastrophic shifts in ecosystems. Nature 413:591-596.

Schluter, D. 2000. The ecology of adaptive radiation. Oxford University Press, Oxford, UK.

Schluter, D. 2009. Evidence for ecological speciation and its alternative. Science 323:737-741.

Schmitz, O. 2010. Resolving ecosystem complexity. Princeton University Press, Princeton, New Jersey, USA.

Schoener, T. W. 2011. The newest synthesis: understanding the interplay of evolutionary and ecological dynamics. Science 331:426-429.

Schröder, A., L. Persson, and A. M. de Roos. 2005. Direct experimental evidence for alternative stable states: a review. Oikos 110:3-19.

Siepielski, A. M., J. D. DiBattista, and S. M. Carlson. 2009. It's about time: the temporal dynamics of phenotypic selection in the wild. Ecology Letters 12:1261-1276.

Sterner, R., and J. Elser. 2002. Ecological stoichiometry: the biology of elements from molecules to the ecosystem. Princeton University Press, Princeton, New Jersey, USA.

Stinchcombe, J., and M. Rausher. 2002. The evolution of tolerance to deer herbivory: modifications caused by the abundance of insect herbivores. Proceedings of the Royal Society B 269:1241-1246.

Stomp, M., J. Huisman, F. de Jongh, A. J. Veraart, D. Gerla, M. Rijkeboer, B. W. Ibelings, U. I. A. Wollenzien, and L. J. Stal. 2004. Adaptive divergence in pigment composition promotes phytoplankton biodiversity. Nature 432:104-107.

Thompson, J. N. 1998. Rapid evolution as an ecological process. Trends in Ecology and Evolution 13:329-332.

Thompson, J. 2005. The geographic mosaic of coevolution. University of Chicago Press, Chicago, Illinois, USA.

Turner, J. S. 2002. The extended organism: the physiology of animal-built structures. Harvard University Press, Cambridge, Massachusetts, USA.

Urban, M. C., M. Leibold, P. Amarasekare, L. DeMeester, R. Gomulkiewicz, M. E. Hochberg, C. A. Klausmeier, N. Loeuille, C. Demazancourt, and J. Norberg. 2008. The evolutionary ecology of metacommunities. Trends in Ecology and Evolution 23:311-317.

Van Dyken, J. D., and M. J. Wade. 2012. Origins of altruism diversity II: runaway coevolution of altruistic strategies via "reciprocal niche construction". Evolution 66:2498-2513.

Vanni, M. J., C. D. Layne, and S. E. Arnott. 1997. "Topdown" trophic interactions in lakes: effects of fish on nutrient dynamics. Ecology 78:1-20.

Vanormelingen, P., W. Vyverman, D. De Bock, K. Van der Gucht, and L. De Meester. 2009. Local genetic adaptation to grazing pressure of the green alga Desmodesmus armatus in a strongly connected pond system. Limnology and Oceanography 54:503.

Verreydt, D., L. De Meester, E. Decaestecker, M.-J. Villena, K. Van Der Gucht, P. Vannormelingen, W. Vyverman, and S. A. J. Declerck. 2012. Dispersal-mediated trophic interactions can generate apparent patterns of dispersal limitation in aquatic metacommunities. Ecology Letters 15:218-226.

Vincent, T., and J. Brown. 2005. Evolutionary game theory, natural selection, and Darwinian dynamics. Cambridge University Press, Cambridge, UK.

Wade, M. J., and S. Kalisz. 1990. The causes of natural selection. Evolution 44:1947-1955.

Walsh, M. R. 2013. The evolutionary consequences of indirect effects. Trends in Ecology and Evolution 28:23-29.

Walsh, M. R., J. P. DeLong, T. C. Hanley, and D. M. Post. 2012. A cascade of evolutionary change alters consumerresource dynamics and ecosystem function. Proceedings of the Royal Society B 279:3184-3192.

Werner, E. E., and S. Peacor. 2003. A review of trait-mediated indirect interactions in ecological communities. Ecology 84:1083-1100.

Wright, J., P. Gribben, and J. Byers. 2012. Invasive ecosystem engineer selects for different phenotypes of an associated native species. Ecology 93:1262-1268.

Wright, J. P., and C. G. Jones. 2006. The concept of organisms as ecosystem engineers ten years on: progress, limitations, and challenges. BioScience 56:203.

Yoder, J. B., et al. 2010. Ecological opportunity and the origin of adaptive radiations. Journal of Evolutionary Biology 23:1581-1596. 